\title{
Mujeres, hermanas e hijas: el mecenazgo femenino en la familia de Alfonso $\mathrm{VI}^{*}$
}

\author{
Therese MARTIN \\ Consejo Superior de Investigaciones Científicas, Madrid
}

Dentro del marco de este trabajo, no se puede relatar la historia completa del mecenazgo de todas las mujeres de la familia de Alfonso VI ya que el empeño rebasaría ampliamente el objetivo propuesto ${ }^{1}$. Como bien es sabido, contó con dos hermanas muy activas en su corte además de siete consortes (tanto esposas legítimas como concubinas reconocidas) y cinco hijas (fig. 1). Dado que un estudio

\begin{tabular}{|c|c|}
\hline \multicolumn{2}{|c|}{ Consortes de Alfonso VI (con descendencia en negrita) } \\
\hline \multicolumn{1}{|c|}{ Esposas } & Concubinas \\
\hline $\begin{array}{l}\text { Inés de Aquitania, 1074-1077/8 } \\
\text { Constanza de Borgoña, 1079-1093 } \\
\text { ca. 1080 Urraca }\end{array}$ & $\begin{array}{c}\text { Jimena Muñoz, ca. 1081 - ? } \\
\text { ca. 1082, Elvira } \\
\text { ca. 1084, Teresa }\end{array}$ \\
& $\begin{array}{c}\text { Zaida/Isabel, ca. 1091-1107? } \\
\text { ca. 1093, Sancho }\end{array}$ \\
\hline $\begin{array}{l}\text { Berta de Lombardía/Toscana, 1094-1100 } \\
\text { Isabel (¿de Francia?), 1100-1107 } \\
\text { ca. 1102, Sancha } \\
\text { ca. 1103, Elvira }\end{array}$ & \\
Beatriz (¿de Francia?), 1108-1109 &
\end{tabular}

Fig. 1. Consortes e hijos de Alfonso VI.

* Este estudio forma parte del proyecto de investigación "Reassessing the Roles of Women as 'Makers' of Medieval Art and Architecture" (ERC Starting Grant 2010-2014, no. 263036).

1 Los estudios esenciales para la historia de Alfonso VI y su familia son B.F. ReILly, The Kingdom of Leon-Castile under Alfonso VI, 1065-1109, Princeton, 1988 (disponible en The Library of Iberian Sources On-Line, http://libro.uca.edu/alfonso6/alfonso.htm), trad. El reino de León y Castilla bajo el rey Alfonso VI (1065-1109), Toledo, 1989, y A. Gambra Gutiérrez, Alfonso VI: Cancillería, curia e imperio, I. Estudio, II. Colección diplomática, vols. 62 \& 63, Fuentes y estudios de historia leonesa, León, 1998. Ver también W. Moore, Religious Language and the Construction of Royal Power: León, 1037-1126, tesis doctoral, Columbia University, 2009. 
completo de cada una de estas personas sería tema más bien adecuado a una monografía que a un artículo, se va a indagar en determinados aspectos de algunas de ellas para con ello aproximarnos de manera sintética a la cuestión del mecenazgo femenino de la segunda mitad del siglo XI y el comienzo del XII. Por ser las mejor documentadas este estudio se centrará en cuatro personas: las dos hermanas del rey, Urraca (ob. 1101) y Elvira (ob. 1099), su segunda esposa, Constanza de Borgoña (ob. 1093) y su hija primogénita, Urraca (ob. 1126). Estas mujeres proporcionan un abanico amplio de los papeles que desempeñaron las mujeres dentro de los niveles más elitistas de la sociedad medieval ya que entre ellas se encuentran unas infantas solteras, una reina consorte y una reina heredera. Es de esperar que un enfoque de esta naturaleza permita acercarnos a metodologías y conclusiones globales que se puedan aplicar al tema en general y no sólo a unos contados personajes. Porque lo realmente interesante de la cuestión del mecenazgo femenino no radica en la elaboración de un catálogo a secas sino en la posibilidad de adentrarse cada vez más en la significación del acto dentro del contexto histórico.

Tradicionalmente, la historia del arte medieval ha tratado la figura de la mujer principalmente como imagen, un objeto pasivo, tendencia que está remitiendo ante el creciente interés por investigar las maneras en las que ellas ejercían la autoridad a través de la cultura visual. La investigación más vigente ha constatado que una de las vías de acceso al poder lo constituyó el patrocinio sobre el arte y la arquitectura, sobre todo religiosa, sea de objetos preciosos como por poner un ejemplo el cáliz donado por la infanta Urraca, hermana del rey, a San Isidoro de León (tratado en detalle más adelante) o bien las concesiones de gran envergadura a entidades monásticas como sería el derecho de acuñar que la hija del rey y tocaya de su tía otorgó al monasterio de Sahagún ${ }^{2}$. Apoyándonos en las investigaciones que se han multiplicado desde los años noventa, hoy se entiende que tales obsequios conllevaban numerosos fines, entre ellos enriquecer la iglesia, cubrir las necesidades de los religiosos y cumplir con la obligación espiritual de la donante. Pero es importante recordar que todo ello redundaba además en su propio prestigio satisfaciendo algunas finalidades terrenales o políticas ${ }^{3}$.

2 Documento publicado en I. RuIz Albi, La reina doña Urraca (1109-1126), cancillería y colección diplomática, León, 2003, pp. 478-480. En la carta se especifica que el abad de Sahagún tiene autoridad sobre la acuñación pero los beneficios se dividen en tres partes iguales entre Sahagún, la reina y el monasterio femenino de San Pedro de Dueñas.

3 Entre la ya amplia bibliografía sobre el mecenazgo femenino en la Edad Media, caben destacar algunos estudios que se centran en las conexiones con la autoridad: C.H. BERMAN, "Women as Donors and Patrons to Southern French Monasteries in the Twelfth and Thirteenth Centuries", The Worlds of Medieval Women, eds. C.H. Berman, C. Cornell, J.R. Rothschild, Morgantown, W. Va., 1985, pp. 53-68; M. Caviness, "Patron or Matron? A Capetian Bride and a Vade Mecum for her Marriage Bed", Speculum, 68 (1993), pp. 333-362 (también en Studying Medieval Women: Sex, Gender, Feminism, ed. N. F. PARTnER, Cambridge, Ma., 1993, pp. 31-60, con la adición de una bibliografía anotada, pp. 175-181); EAD., "Anchoress, Abbess and Queen: Donors and Patrons or Intercessors and Matrons?" The Cultural Patronage of Medieval Women, ed. J. H. McCAsH, Athens, 1996, pp. 105-153; R.S. Humphreys, "Women as Patrons of Religious Architecture in Ayyubid Damascus", Muqarnas: An Annual on Islamic Art and Architecture, 11 (1994), pp. 35-54; A. GAJEwsKI, "Recherches sur 
Si esta pluralidad de fines ya se capta casi a primera vista tras la historiografía actual, se hacen necesarias preguntas novedosas que profundicen en las estrategias de las mujeres para revelar cómo el mecenazgo servía para conseguir sus metas, siempre desde el contexto histórico dentro del cual cada una vivía. ¿Las actividades artístico-arquitectónicas se pueden calificar como subversivas o con ellas cumplían los papeles que se les había asignado la sociedad? ¿El mecenazgo fue esencialmente «femenino», o reflejaba su estatus dentro de las estructuras sociales como función de su clase o condición? Resulta algo reduccionista equiparar solo por cuestión de género, por poner un ejemplo, el acto de una aldeana que dona un vestido o una sábana para cubrir el altar de su parroquia ${ }^{4}$ con la ofrenda de propiedad por parte de una infanta a una gran abadía en tierras lejanas ${ }^{5}$. Se relacionan no solo por proceder de mujeres sino por ser regalos interesados: en el primer caso se busca manifestarse ante los ojos de los vecinos en el altar, lugar en el que la presencia de toda mujer estaba prohibida, pero tras el segundo se constatan cuestiones geopolíticas que se aplicarían igual en caso de que fuera el mecenas un hombre ${ }^{6}$.

Las artes suntuarias ofrecen una rica vía para la investigación del patrocinio a pesar de ser comprendidas más por noticias documentales que por piezas concretas que se han conservado hasta nuestros días. El referido cáliz (fig. 2) brinda un ejemplo modélico: hecho de dos copas de ágata que se suelen identificar como romanas, se modernizaron al unirlas dentro de un nuevo armazón de oro decorado con filigranas y

l'architecture cistercienne et le pouvoir royal: Blanche de Castille et la construction de l'abbaye du Lys", Art et Architecture à Melun au Moyen Age, ed. Y. Gallet, Paris, 2000, pp. 223-254; D.F. RugGles (ed.), Women, Patronage, and Self-Representation in Islamic Societies, Albany, 2000; J. JARRETT, "Power over Past and Future: Abbess Emma and the Nunnery of Sant Joan de les Abadesses", Early Medieval Europe 12, no. 3 (2003), pp. 229-258; T. MARTIN, "The Art of a Reigning Queen as Dynastic Propaganda in Twelfth-Century Spain", Speculum, 80, no. 4 (October 2005), pp. 1134-1171; F. PeredA, "Mencía de Mendoza (+1500), Mujer del I Condestable de Castilla: El significado del patronazgo femenino en la Castilla del siglo XV", Patronos y coleccionistas. Los condestables de Castilla y el arte (siglos XV-XVII), Valladolid, 2005, pp. 11-119; V.C. Raguin y S. Stanbury (eds.), Women's Space: Patronage, Place, and Gender in the Medieval Church, Albany, 2005; J. YARZA LuAces, Isabel la Católica: Promotora Artística, León, 2005; E. GuTwIRTH, «Quilusin: el mecenazgo femenino medieval", La mujer judía, ed. Y. Moreno Koch, Córdoba, 2007, pp. 107-128; J.F. Hamburger y S. Marti (eds.), Crown and Veil: Female Monasticism from the Fifth to the Fifteenth Centuries, Nueva York, 2008; K.A. SмIтH y S. Wells (eds.), Negotiating Community and Difference in Medieval Europe: Gender, Power, Patronage and the Authority of Religion in Latin Christendom, Leiden, 2009.

4 K.L. FrenCH, “' 'I Leave My Best Gown as a Vestment:' Women's Spiritual Interests in the Late Medieval English Parish", Magistra: A Journal of Women's Spirituality in History, 4/1 (1998), pp. 57-77.

5 Tal fue el caso en febrero de 1109 cuando la todavía infanta Urraca (ob. 1126) "totius Galletie domna", dona el monasterio de San Vicente de Pombeiro a la abadía borgoñona de Cluny. Lo hace de propia uoluntate et consilio patris mei, imperatoris domni Adefonsi, cuya muerte pocos meses más tarde la convertiría en reina de León y Castilla. Publicado en M. Recuero Astray, M. GonzÁlez Vázquez y P. Romero Portilla, Documentos medievales del Reino de Galicia: Doña Urraca (1095-1126), A Coruña: Santa Comba, 2002, p. 58.

6 De hecho, la donación referida en la nota anterior demuestra que Urraca tenía conciencia de la importancia de mantener las buenas relaciones con Cluny que habían establecido sus padres y abuelos. Para una reciente aproximación a esta cuestión, ver A.G. GoRDo Molina, "La reina Urraca I de León y la Orden de Cluny", Un magisterio vital: historia, educación y cultura. Homenaje a Héctor Herrera Cajas, eds. J.L. Widow, Á. Pezoa y J. Marín, Santiago de Chile, 2008, pp. 313-323. También T. Martin, Queen as King: Politics and Architectural Propaganda in Twelfth-Century Spain, Leiden, 2006, pp. 182-185. 
joyas, probablemente en algún momento posterior a 1063 cuando se consagró la iglesia de sus padres bajo la dedicación del nuevo santo patrón, Isidoro de Sevilla (ob. 636) ${ }^{7}$. Llama la atención el pequeño rostro de pasta vítrea en la parte superior del cáliz que se alinea axialmente con el nombre de la comitente en la zona inferior: IN NOMINE D[OMI] NI VRRACA FREDINA[N]DI. Algunos autores han querido ver en ello un retrato de Urraca ${ }^{9}$, teoría difícilmente sostenible por el pelo que se perfiló con cuidado alrededor de la cara correspondiente al uso típico de las representaciones masculinas ${ }^{10}$. Como se sabe, en la plena Edad Media la mujer honrada se retrataba velada, tal y como se ve en

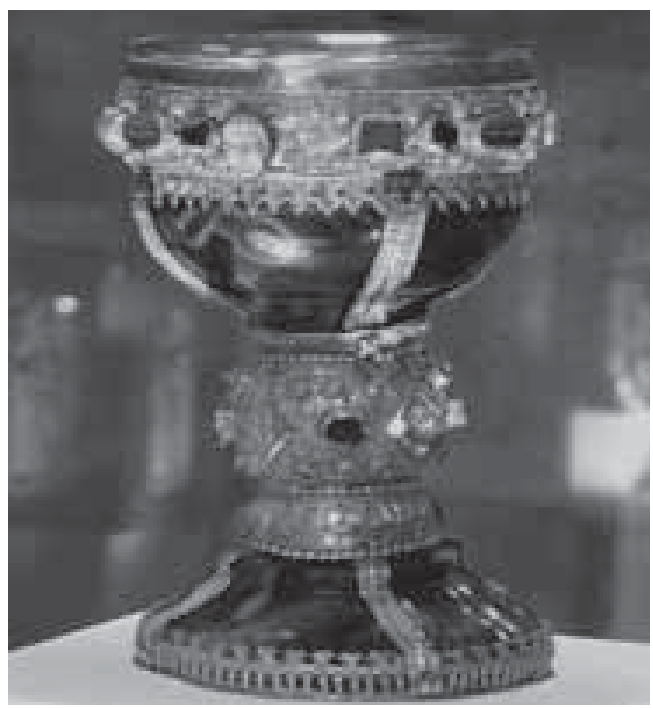

Fig. 2. Cáliz de la infanta Urraca, San Isidoro de León, c. 1063 (T. Martin)

7 The Art of Medieval Spain, AD 500-1200, Metropolitan Museum of Art, Nueva York, 1993, pp. 254255; Maravillas de la España Medieval. Tesoro Sagrado y Monarquía, 2 vols., Madrid, 2001, p. 335. Sobre el tesoro de San Isidoro, ver los estudios de A. Franco Mata, "Arte medieval cristiano leonés en el Museo Arqueológico Nacional”, Tierras de León no. 71, año 28 (1988), pp. 27-59; EAD., "El tesoro de San Isidoro y la monarquía leonesa», Boletín del Museo Arqueológico de Madrid 9/1-2 (1991), pp. 35-68; EAD., «La eboraria de los reinos hispánicos durante los siglos XI y XII", Codex Aquilarensis, Actas del I Curso sobre la Península Ibérica y el Mediterráneo durante los siglos XI y XII, 1996, Aguilar de Campoo, 1998, pp. 145-166, esp. 154. La reciente publicación de S. ANDRÉs ORDAX, "El tesoro de la monarquía leonesa”, Real Colegiata de San Isidoro, relicario de la monarquía leonesa, eds. C. Robles García, F. Llamazares Rodríguez, León, 2007, pp. 168-193, incluye una magnífica fotografía de gran tamaño del cáliz.

8 Agradezco la ayuda de Genevra Kornbluth y Jeffrey Spier, quienes me han orientado sobre la cuestión de las gemas medievales. Ambos especialistas han coincidido en fechar el busto del Cáliz de Urraca en el siglo XI. A la misma conclusión llegó J. A. MorÁIs MorÁn, "Pervivencias de la antigüedad clásica en la Edad Media hispana. El spolium in se: a propósito del cáliz de doña Urraca”, Perfiles de Grecia y Roma. Actas del XII Congreso Español de Estudios Clásicos, Valencia 22-26 oct. 2007, Madrid, 2009, pp. 904-927.

9 La idea fue sugerida por primera vez por T. CATARELla, "Doña Urraca and her Brother Alfonso VI: Incest as Politics", La corónica: A Journal of Medieval Hispanic Languages, Literatures \& Cultures 35/2 (2007), pp. 39-68, esp. 48: "In keeping with the dedicatory inscription, the tradition of sponsor portrayals, and the sheer individuality of the face, this might well be another donor portrait of Urraca". Recientemente se ha vuelto a insistir en esta identificación ("con toda probabilidad un retrato de la infanta"): F. PRADO-VILAR, "Lacrimae rerum: San Isidoro de León y la memoria del padre”, Goya, 328 (2009), pp. 195-221, esp. 216, n. 13.

10 Ya en 1993, John Williams lo identificó como una "masculine head" en Art of Medieval Spain, pp. 254-255. Sirven a modo de comparación dos ejemplos italianos de la Alta Edad Media (probablemente ss. VII-VIII) de bustos femeninos vistos de frente en los que el pelo visible está sujeto por una diadema que cruza la frente o tapado en su mayor parte por un velo que arranca de la parte alta de la cabeza, siguiendo el modelo romano: E. GAGETTI, “ 'Ex romano vitro splendentes lapilli.' Ricezione di iconografie della glittica ellenisticoromana in cammei vitrei altomedievali”, Sertum Perusinum gemmae oblatum: docenti e allievi del Dottorato di Perugia in onore di Gemma Sena Chiesa (Quaderni di ostraka, vol. 13), Nápoles, 2007, pp. 161-196, esp. figs. 3 y 5 . El ejemplo leonés no muestra evidencia de ningún elemento que restrinja o sujete el cabello. 
la imagen del Tumbo A en la que la misma infanta Urraca se representa en el acto de ofrecer una carta de donación a la Catedral de Santiago de Compostela (fig. 3) ${ }^{11}$. Más bien, esta pieza parece responder al interés por incluir gemas antiguas dentro de la orfebrería eclesiástica por su significación imperial, práctica muy arraigada en el mundo otoniano de los siglos $\mathrm{X}$ y XI ${ }^{12}$ como se ven en los célebres crucifijos de Lotario, hoy en la Catedral de Aquisgrán (finales del s. X) y del Arzobispo Herimann de Colonia (ca. 1050) ${ }^{13}$. En el primero, un camafeo del emperador Augusto (63 a. C. - 14 d. C.) de perfil ocupa el espacio central del reverso de la cruz mientras que en el segundo la cara del Crucificado se conforma mediante un busto femenino en lapislázuli que ha sido identificado con la emperatriz Livia

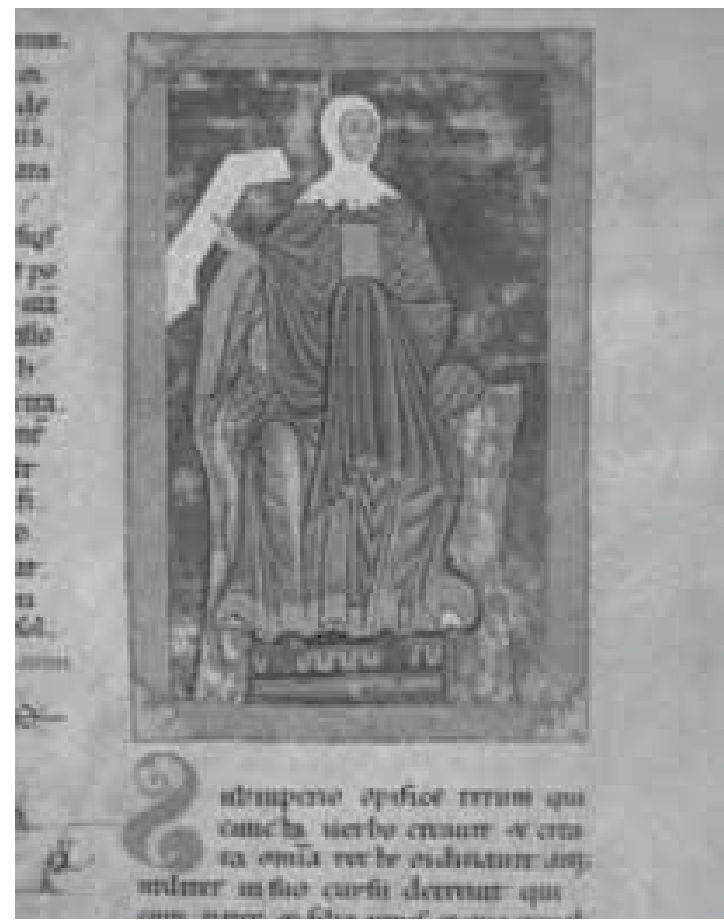

Fig. 3. Infanta Urraca, Tumbo A, 1129-1134 (con el permiso de Archivo de la Catedral de Santiago de Compostela). (58 a.C. - 29 d.C.). Ambas piedras preciosas enlazaban los donantes otonianos con el pasado imperial para otorgarles mayor legitimidad dentro del mundo cristiano actual.

Con toda probabilidad la infanta Urraca conocía la usanza germánica y la compartía no solo a partir de la reutilización de las copas antiguas de ágata para constituir un cáliz sino también en el trazado de una cruz desaparecida, como se

11 Para un estudio reciente sobre las imágenes del Tumbo A con bibliografía anterior, ver R. SÁNCHEZ AmeiJeiras, "Sobre las modalidades y funciones de las imágenes en el Tumbo A", Tumbo A. Índice de los Privilegios Reales, que contiene este Libro intitulado de la Letra A. Original conservado en la Biblioteca de la Catedral de Santiago. Estudios, dir. C. Olmos García-Calamarte, Madrid, 2008, pp. 143-216.

12 Entre otros muchos ejemplos, ver el relicario en forma de un brazo de San Blas en Braunschweig identificado a través de una inscripción con la Condesa Gertrudis (ob. 1077), mecenas conocida sobre todo por su famoso altar portátil. Ver A. KRUG, "Die antiken Gemmen am Armreliquiar des hl. Blasius in Braunschweig", Der Welfenschatz und sein Umkreis, eds. J. Ehlers, D. KöTzsche, Mainz am Rhein, 1998, pp. 93-109; P. CoRBET, "L'autel portatif de la comtesse Gertrude de Brunswick (vers 1040). Tradition royale de Bourgogne et conscience aristocratique dans 1'Empire des Saliens," Cahiers de civilisation médiévale 34 (1991), pp. 97-120.

13 Resúmenes de la bibliografía y fotografías detalladas de los dos crucifijos se encuentran en G. Minkenberg, "Cruz de Lotario de la Cámara del Tesoro de la Catedral de Aachen", y U. Surmann, "Cruz de Herimann, Köln”, en Signum Salvtis: Cruces de orfebrería de los siglos V al XII, ed. C. GARCÍA DE CASTRO VALDÉs, Oviedo, 2008, pp. 181-187 y 250-254. 
verá seguidamente. Al no contar con una joya de época clásica para hacer juego con las tazas ¿podría ser que la mecenas solicitara al escultor que lo hiciera en un estilo antiquizante ${ }^{14}$, tal y como había sido el caso del camafeo all'antica del Cofre de Teudérico ${ }^{15}$ ? Este relicario del final del siglo VII se hizo para la abadía suiza de Saint-Maurice d'Agaune; por su inscripción detallada, se saben los nombres de los patronos, tanto un clérigo como una pareja aparentemente laica, y de los orfebres:

\section{TEUDERIGUS PRESBITER IN HONURE S(AN)C(TI) \\ MAURICII FIERI IUSSIT. AMEN. \\ NORDOALAUS ET RIHLINDIS ORDENARUNT FABRIGARE. UNDIHO ET ELLO FICERUNT.}

El presbítero Teuderigus mandó hacer en honor del santo Mauricio. Amen.

Nordoalaus y Rihlindis ordenaron fabricarlo.

Undiho y Ello lo hicieron.

La inscripción hace explícita la manera en la que la producción artístico-religiosa de la Edad Media era una obra de colaboración, frecuentemente concebida por un clérigo, pagada por laicos que podían ser hombres, mujeres o ambos en conjunto, y elaborada por artistas que solían trabajar en talleres.

Más allá del cáliz, otra ofrenda concedida por la hermana del rey la describe su contemporáneo el obispo Pelayo de León en 1073, hoy desgraciadamente desaparecida. En términos algo confusos que detallan tanto una cruz plateada como un crucifijo con un cuerpo-relicario que la infanta obsequió a la catedral leonesa, Patrick Henriet y Jean-Marie Sansterre lo explican no como dos piezas separadas sino como un ensamblaje de una "cruz grande de plata ornada de pie-

14 Comparar el busto del cáliz de San Isidoro con los camafeos antiguos que representan Dionisio y Attis en el relicario de San Blas (KRUG, "Die antiken Gemmen", p. 97, figs. 5a y 5b).

15 Para un análisis centrado en el camafeo medieval, GagetTI, "Ex romano vitro splendentes lapilli", esp. 179-183, figs. 19 y 20. Ver sugerencias sobre la identificación del personaje retratado en el camafeo junto con bibliografía anterior en D. ThurRe, "Les trésors ecclésiastiques du haut Moyen âge et leur constitution. Èclairage à travers deux examples helvétiques: Saint-Maurice d'Agaune et Sion", Les Trésors des sanctuaries, de l'Antiquité à l'époque romane (Cahiers du Centre de Recherches sur l'Antiquité Tardive et le Haut Moyen Âge, VII), ed. J.P. CAILlet, Paris-Nanterre, 1996, pp. 43-81. Otros muchos ejemplos de gemas medievales han sido estudiado por H. Wentzel, "Mittelalterliche Gemmen. Versuch einer Grundlegung", Zeitschrift des Deutschen Vereins für Kunstwissenschaft 8 (1941), pp. 45-98; ID., "Mittelalterliche Gemmen in den Sammlungen Italiens", Mitteilungen des Kunsthistorischen Institutes in Florenz 7 (1953-6), pp. 239-278; ID., "Die Vier Kameen im Aachener Domschatz und die französische Gemmenschneidekunst des 13. Jahrhunderts", Zeitschrift für Kunstwissenschaft 8 (1954), pp. 1-18; ID., "Die 'Croce del Re Desiderio' in Brescia und die Kameen aus Glas und Glaspaste im frühen und hohen Mittelalter”, Stucchi e mosaici alto medioevali ( $8^{\mathrm{eme}}$ Congrès internationale pour l'étude du haut moyen-age, Vicenza, 1959), Milán, 1962, pp. 303-320. 
dras preciosas, sobre la que se colocó el lignum Domini crucifixo decoratum"16. Tradicionalmente se ha asociado el llamado Cristo de Carrizo (fig. 4) con el crucifijo donado a la catedral por la infanta, posibilidad que no descartamos por la semejanza del estilo con la eboraria leonesa aunque resulta un tanto complicado imaginar un cuerpo de 33 centímetros colocado sobre una cruz grande, quizá debido al gusto moderno por la proporción entre partes ${ }^{17}$. También habría que tener en cuenta el elevado coste del marfil cuya misma naturaleza impondría restricciones de tamaño pero no por eso el resultado sería menos suntuoso. La perdida cruz grande de la Catedral de León sería destinada a estar a la vista de un público amplio, no un objeto de reducidas dimensiones adecuado para una procesión o para la decoración de un altar como otros que se verán más adelante. Semejante debió de ser el crucifijo, también perdido, que la infanta Urraca donó a San Isidoro. En 1732, José Manzano lo describió como una cruz que medía unos dos metros de altura ("dos varas y media y lo ancho de los brazos de vara y media"), chapada de oro y plata y orna-

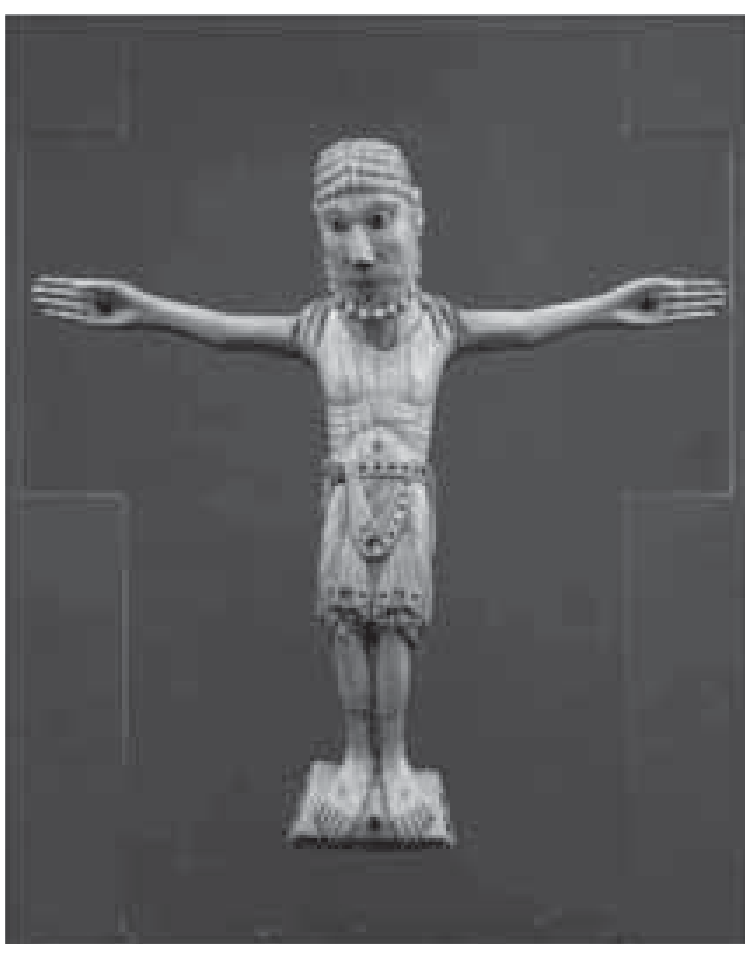

Fig. 4. Cristo de Carrizo, último tercio del s. XI (R. Rossner). mentada con esmaltes y piedras preciosas alrededor de un cuerpo de marfil ${ }^{18}$. Como se sabe, en contraste con el busto masculino que decora el cáliz de Urraca, en esta pieza sí que hubo una imagen de la infanta: según Manzano, "una Efigie de oro de medio relieve, de Doña Urraca, con esta inscripción: Urraca, Regis Ferdinandi filia \& Sanchiae Reginae

16 P. Henriet y J.-M. SAnsterre, “De 'l'inanimis imago' à 'l'omagem mui bella': méfiance à l'égard des images et essor de leur culte dans 1'Espagne médiévale (VII-XIII siècle)”, Edad Media: revista de historia 10, 2009, pp. 37-92, esp. 56.

17 M.M. Estella Marcos, La escultura del marfil en España, Románica y Gótica, Madrid, 1984, pp. 24-26 con bibliografía anterior. Ver también los estudios de A. Franco en la nota 7; Art of Medieval Spain, pp. 244-250; Maravillas de la España Medieval, pp. 230-231, 384-385.

18 J. Manzano, Vida y portentosos milagros del glorioso San Isidro, arzobispo de Sevilla, con una breve descripción de su magnífico templo y real casa del mismo señor San Isidro en la muy noble ciudad de León, Salamanca, 1732 , pp. 352 y 383. 
donavit"19. La descripción hecha por el Padre Manuel Risco en 1792 no se extendía en cuanto a la forma y las materias, ni de la cruz ni de la figura de Cristo; en cambio, se perfiló con más nitidez el retrato de la infanta:

Debaxo de los pies del crucifixo se lee esta palabra: MISERICORDIA, y luego: VRRACCA FREDINANDI REGIS ET SANCIA REGINA FILIA; $y$ en la parte inferior de la Cruz se representa la misma Doña Urraca arrodillada, juntas, elevadas, y extendidas las manos, repitiéndose su nombre, cuyas letras comienzan sobre su cabeza, y baxan por delante, extendiéndose casi tanto como la figura ${ }^{20}$.

Los paralelos más cercanos a esta representación de la donante en la parte inferior del crucifijo proceden otra vez de ejemplos otonianos. Varios autores han notado las relaciones de la cruz de finales del siglo X encargada por Mathilde de Essen (ob. 1011), nieta del emperador Otto I, con la orfebrería leonesa por el estilo del Crucificado ${ }^{21}$; nosotros subrayamos además las analogías con el mecenazgo femenino por parte de una mujer religiosa en nombre de sí misma y de su hermano el soberano. En esta cruz otoniana la abadesa y el conde se retratan en esmalte por debajo de la figura de Cristo. Ricamente ataviados, se muestran de pie y elevan entre ellos una cruz procesional flanqueada por sus nombres (MAHTHILD ABBA, OTTO DUX). Se reconoce a Mathilde como la mecenas principal por su posición inusual a la derecha del Salvador ${ }^{22}$. Sin embargo, aún más estrechas habrían sido las semejanzas entre el retrato de la infanta Urraca en el crucifijo que donó a San Isidoro y el ejemplo gemado que la reina Gisela de Hungría (ob. 1060/65), consorte del rey Esteban y hermana del emperador Enrique II, otorgó al monasterio de Ratisbona en nombre de su madre, Gisela de Borgoña, por la representación de las mujeres en oro repoussé (fig. 5a) ${ }^{23}$. Madre e hija se encuentran a los pies de Cristo en actitud de oración con las manos elevadas y las piernas dobladas todo lo que permite el estrecho espacio (fig. 5b). El mecenazgo de la reina se resalta textualmente con inscripciones prolijas, la principal colocada en los cuatro extremos del anverso de la cruz para rodear la figura de Jesús. En esta cara se lee en sentido contrario a las agujas del reloj:

\section{ECCE SALVS VITE P[ER] QVA[M] MORS MORTVA MORTE VNDE SVAE MATRISQVE ANIMAE POSCENDO SALVTE[M]}

\footnotetext{
19 Manzano, Vida y portentosos milagros, p. 383.

20 M. Risco, Iglesia de Leon, y monasterios antiguos y modernos de la misma ciudad, Madrid, 1692, pp. 146-147.

${ }^{21}$ S. Moralejo Alvarez, "AArs sacra' et sculpture romane monumentale: le trésor et le chantier de Compostelle", Les Cahiers de Saint-Michel de Cuxa, 2 (1980), pp. 189-238 (también en Patrimonio artístico, t. I, pp. 161-199 [ver nota 25]). Para buenas ilustraciones y bibliografía anterior, ver K.G. BeucKers y B. FALK, "Cruz de Otto y Mathilde, Essen”, Signum Salvtis, pp. 177-180.

22 Para una imagen comparable presente en un manuscrito anglo-sajón del siglo XI, ver E.C. PARKER, "The Gift of the Cross in the New Minster Liber Vitae", Reading Medieval Images: The Art Historian and the Object, eds. E. Sears y T.K. Thomas, Ann Arbor, 2002, pp. 177-186.

23 S. Heym, "Cruz de la reina Gisela, Regensburg”, Signum Salvtis, pp. 218-223.
} 

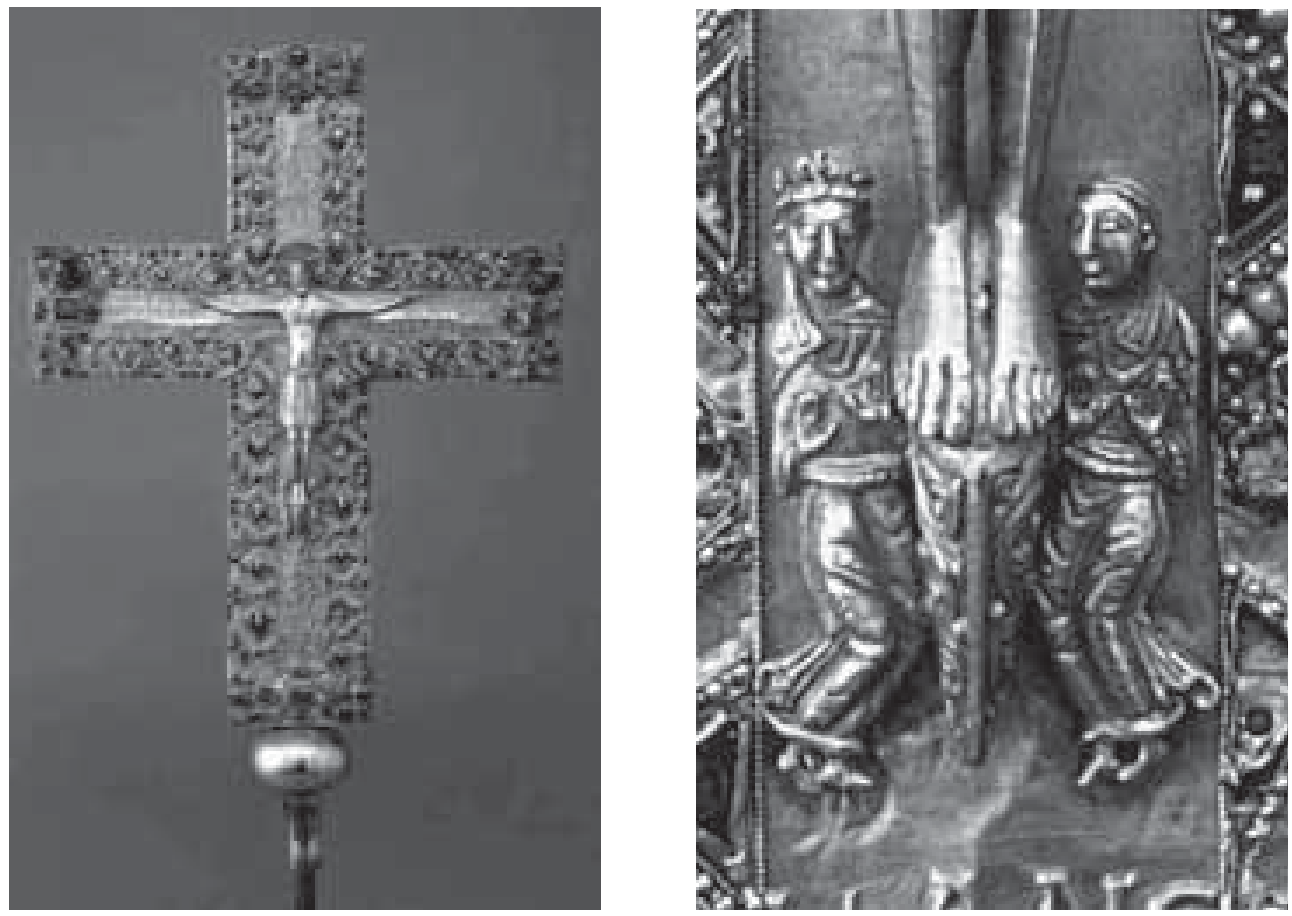

Fig. 5a y 5b. Crucifijo de la reina Gisela de Hungría, s. XI (con el permiso de la Bayerische Vewaltung der staatlichen Schlösser, Gärten und Seen).

\section{HANC REGINA CRVCEM FABRICARI GISILA IVSSIT}

(con esta frase se subrayan las figuras de las dos damas)

\section{QVAM SI QVIS DEMIT HINC DA[M]NETVR MORTE P[ER]ENNI}

He ahí la Salvación de la Vida, por la que la Muerte fue muerta por la Muerte. Por lo que, suplicando por la salvación de su alma y la de su madre, la reina Gisela hizo construir esta cruz.

Si alguien robara esta cruz, que sea castigado con la Muerte Eterna. ${ }^{24}$

Una segunda inscripción se encuentra en la parte inferior del reverso de la cruz: HANC CRVCE[M] GISILA DEVOTA REGINA AD TVMVLV[M] SVE MATRIS GISILE DONARE CVRAVIT ("Gisela la reina devota hizo donar esta cruz a la tumba de su madre Gisela”). Con este regalo la reina de Hungría honró la memoria de su madre en el lugar de su sepultura a la vez que subrayaba los vínculos prestigiosos entre su familia natal y sus nuevos lazos políticos.

24 Traducción de Sabine Heym y José Manuel Rubio Rubio (ver nota anterior). 
Las conexiones entre los emperadores germanos y los soberanos de León que reclamaban semejante título se han estudiado sobre todo mediante las donaciones de Fernando I (ob. 1065) y Sancha (ob. 1067) a la abadía borgoñona de Cluny y el tesoro con el que obsequiaron a su iglesia palatina de San Isidoro probablemente en 1063 para festejar la translación de las reliquias del obispo hispalense ${ }^{25}$. En particular desde el estudio de Manuel Gómez Moreno en 1932, el Arca de San Isidoro ha sido relacionada con las famosas puertas de bronce de San Miguel de Hildesheim (1015) por la semejanza entre las figuras en relieve acabadas con cabezas que se proyectan fuera de la superficie (fig. 6) ${ }^{26}$. Sin embargo, como bien ha señalado Joachim Huber, una analogía más cercana se encuentra en la hoy menos conocida arca denominada la "Grande Châsse de Sion" (Valais, Suiza), relicario fechado hacia 1060-80 (fig. 7a-b) ${ }^{27}$. A pesar del mal estado de conservación, las figuras plateadas demuestran un modo escultórico con bastante afinidad al ejemplo leonés,

25 Documento publicado en E. Martín LóPez, Patrimonio cultural de San Isidoro de León: Documentos de los siglos X-XIII, León, 1995, pp. 26-29. Los estudios esenciales sobre las conexiones entre los soberanos leoneses y alemanes a través del nexo con Cluny incluyen C.J. Bishko, "Liturgical Intercession at Cluny for the King-Emperors of León”, Studia Monastica 3 (1961), pp. 53-76 (también en BishKo, Spanish and Portuguese Monastic History, 600-1300 (Variorum Reprints), London, 1984, con notas adicionales, 77A-82A); ID., "Fernando I y los orígenes de la alianza castellano-leonesa con Cluny", Cuadernos de Historia de España 47-48 (1968), pp. 31-135, Cuadernos de Historia de España 49-50 (1969), pp. 50-116 (también en Studies in Medieval Spanish Frontier History); J. Williams, "Cluny and Spain,” Gesta 27 (1988), pp. 93-102; S. Moralejo, "Cluny et les débuts de la sculpture romane en Espagne," Le Gouvernement d'Hugues de Semur à Cluny (Actes du Colloque scientifique international, Cluny, septembre, 1988), Mâcon, 1990, pp. 405-434; ID., "Cluny y los orígenes de románico palentino: el contexto de San Martín de Frómista," Jornadas sobre el arte de las órdenes religiosas en Palencia, 1989, Palencia, 1990, pp. 9-34 (ambos reeditados en A. Franco Mata, coord., Patrimonio artístico de Galicia y otros estudios. Homenaje al Prof. Dr. Serafin Moralejo Álvarez, 3 tomos, Santiago de Compostela, 2004, t. II, pp. 183-194, 195-206); J.W. Williams, "León: The Iconography of a Capital”, Cultures of Power: Lordship, Status, and Process in Twelfth-Century Europe, ed. T.N. Bisson, Philadelphia, 1995, pp. 231-258 (versión española, "León: iconografía de la capital," El reino de León en la alta Edad Media, IX, ed. J.M. Fernández Catón, León, 1997, pp. 11-37); J.L. Senra Gabriel y Galán, “Ángeles en Castilla: reflexiones en torno a renovación monástica y arquitectura en el siglo XI", Patrimonio artístico, tomo III, pp. 261-274.

26 M. Gómez Moreno, "El arca de las reliquias de San Isidoro de León”, Archivo español de arte y arqueología 7 (1932), pp. 205-112. Ver los estudios de A. FrANCO en la nota 7. Tanto en el estilo como en la iconografía, el Arca de San Isidoro sigue los modelos otonianos, basados en parte en la tradición de la Biblia de Tours según J. Williams, "Tours and the Early Medieval Art of Spain”, Florilegium in Honorem Carl Nordenfalk Octogenarii Contextum, Stockholm, 1987, pp. 197-208. Ver también V. García LoBo, "Las inscripciones medievales de San Isidoro de León", Santo Martino de León (Ponencias del I Congreso internacional sobre Santo Martino en el VIII centenario de su obra literaria, 1185-1985), León, 1987, pp. 371-398; H. Bredekamp y F. Seehausen, "Das Reliquiar als Staatsform. Das Reliquiar Isidors von Sevilla und der Beginn der Hofkunst in León”, Reliquiare im Mittelalter, eds. B. ReudenBACH, G. Toussaint (Hamburger Forschungen zur Kunstgeschichte Bd. V), Berlin, 2005, pp. 137-164.

27 Sobre este relicario son imprescindibles los estudios de Joachim Huber. Sus conclusiones evolucionaron algo entre el artículo de 1993 y la tesis publicada en 1998, esta última resumida en 2005: J. HuBER, "La dite 'Grande Châsse de Sion' dans le trésor du chapitre de Sion en Valais (Suisse), état de la recherche”, Les Cahiers de Saint-Michel de Cuxa 24 (1993), pp. 115-122; ID., Der sogenannte “Grosse Reliquienschrein” im Domschatz zu Sitten: eine Untersuchung zu Geschichte, Kontruktion, Ikonographie und Stil eines mit Silberreliefs verkleideten Reliquienschreins des 11. Jahrhunderts im Alpenraum, Winterthur, 1998; ID., "La Grand Châsse de Sion et la Querelle des Investitures", La Grande Châsse de Sion, chef-d'oeuvre d'orfèvrerie du XIe siècle, eds. K. Anheuser, C. Werner, Paris, 2005, pp. 73-97. 


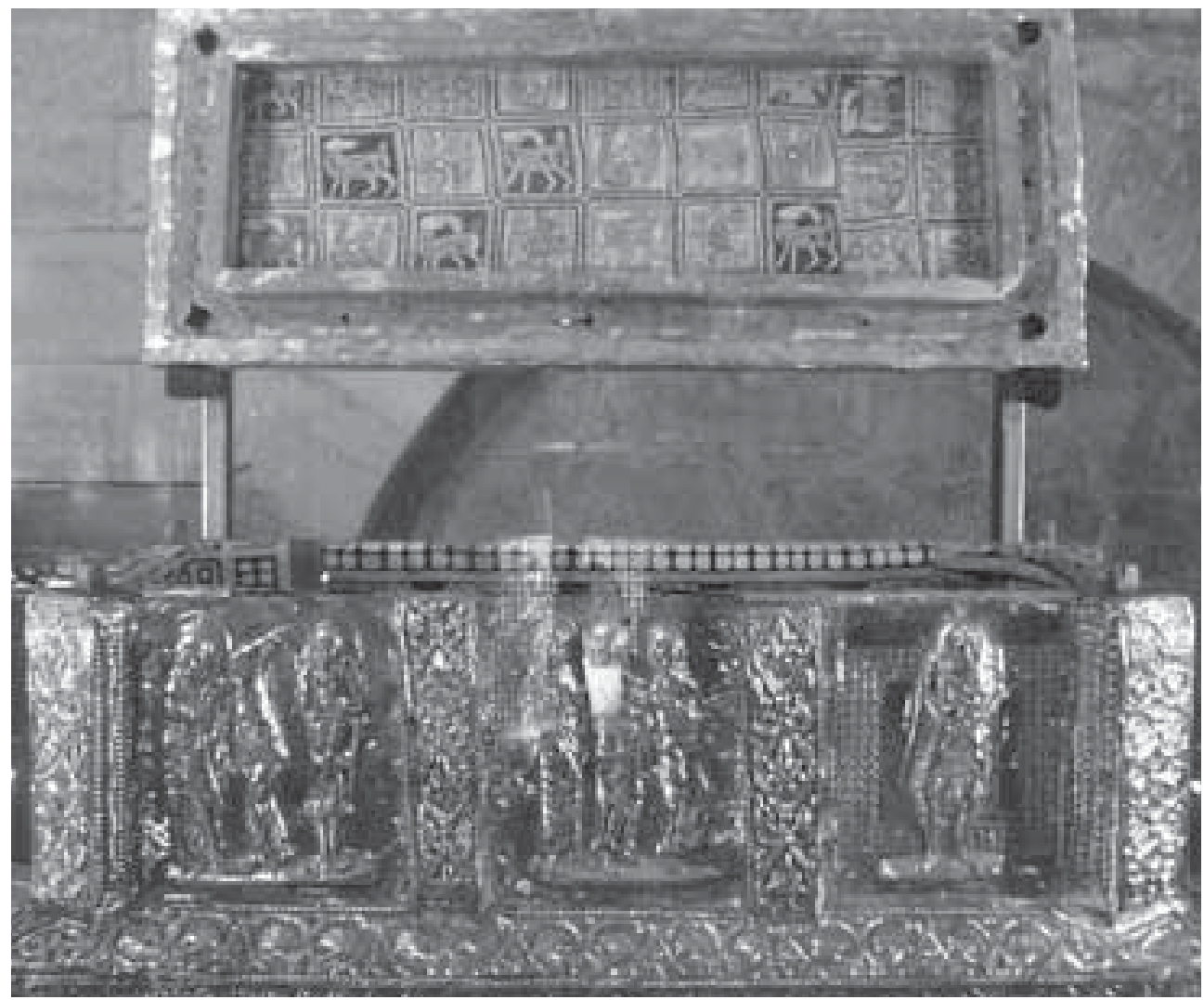

Fig. 6. Arca de San Isidoro, c. 1063 (T. Martin).

sobre todo en las cabezas esculpidas casi en tres dimensiones, si bien los paños del arca suiza se desarrollan con mayor elaboración que los del Arca de San Isidoro. Vínculos tan estrechos como este con el arte germano parecen indicar la presencia de orfebres foráneos en la corte leonesa que trabajaban primero para los padres de Alfonso VI y luego para su hermana Urraca.

Aunque no se puede conjeturar sobre el origen autóctono o extranjero de otras piezas perdidas, tenemos constancia de unas cruces donadas por el rey en nombre de dos de sus esposas al monasterio de los Santos Facundo y Primitivo de Sahagún. La Crónica Anónima las describe así: "una cruz de oro, de maravillosa grandeça, çercada e guarnida de piedras preçiosas" y "otra cruz de oro con muchas piedras preçiosas guarnida"28. Como bien han sugerido María Concepción Cosmen Alonso y María

28 A. Ubieto Arteta (ed.), Crónicas anónimas de Sahagún, Zaragoza, 1987, p. 17. Un gran conjunto de documentos relacionados con el Lignum Crucis se recogen en A. Frolow, La relique de la Vraie Croix. Recherches sur le développement d'un culte, Paris, 1961. Ver también A. García De La Borbolla, "El culto y la devoción al lignum crucis en los reinos occidentales de la península Ibérica (VII-XV)”, Pecia 8/11 (2005), pp. 565-600. 


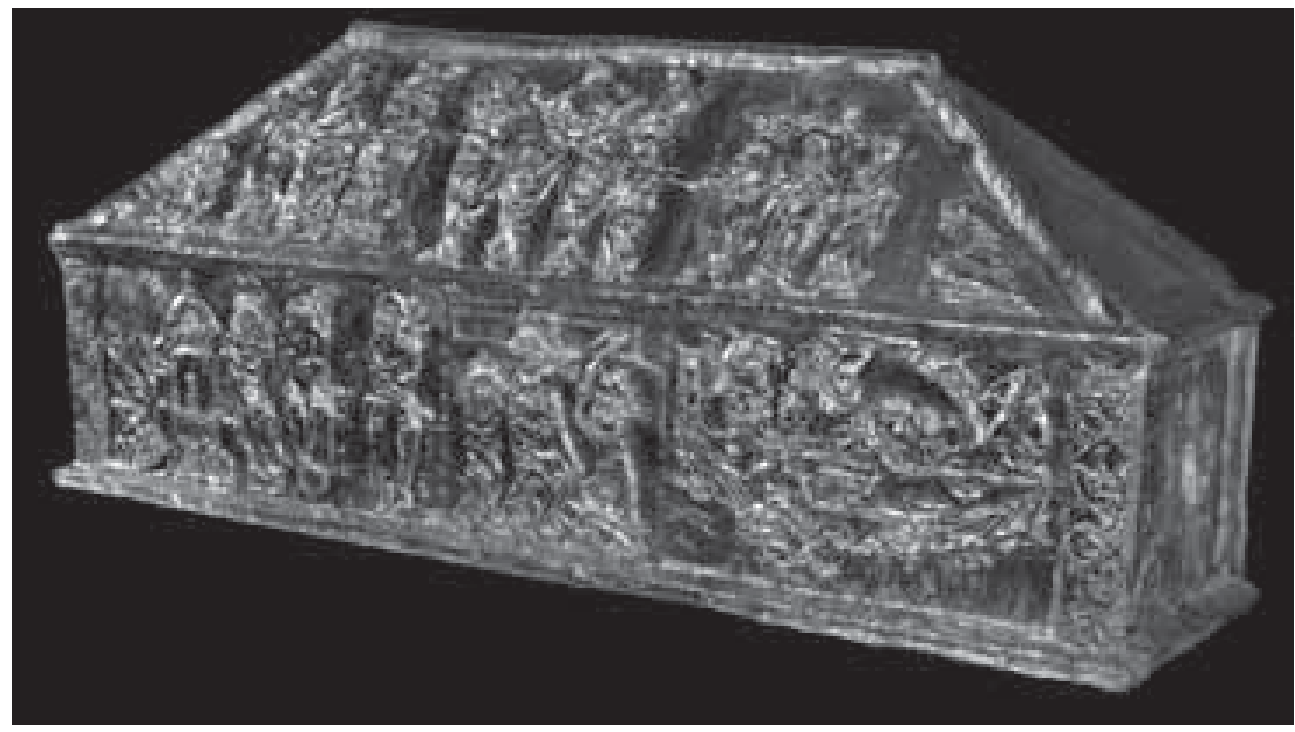

Fig. 7a. Grande Chasse de Sion (con el permiso del Musée de 1'Eveché, Sion).

Victoria Herráez Ortega dentro del marco del Congreso "Alfonso VI y su legado" en octubre de 2009, parece muy probable que estas cruces pertenecieran a las reinas Constanza y Berta durante sus vidas y que fuera por voluntad suya que se donaron a Sahagún a la hora de sus respectivas muertes en 1093 y 1100 . Compartimos esta hipótesis que desafortunadamente no se puede confirmar por falta de testamentos encomendados por ellas ${ }^{29}$. De hecho, de las catorce mujeres que rodearon al monarca durante su largo reinado, ha sobrevivido el testamento final de solo una de ellas, su hermana Elvira (ob. 1099), en el que la gran mayoría de sus legados son de tierras y monasterios, sean heredados del infantazgo o adquiridos durante la vida de la infanta. De las artes suntuarias, dispone únicamente de "mi arca con toda

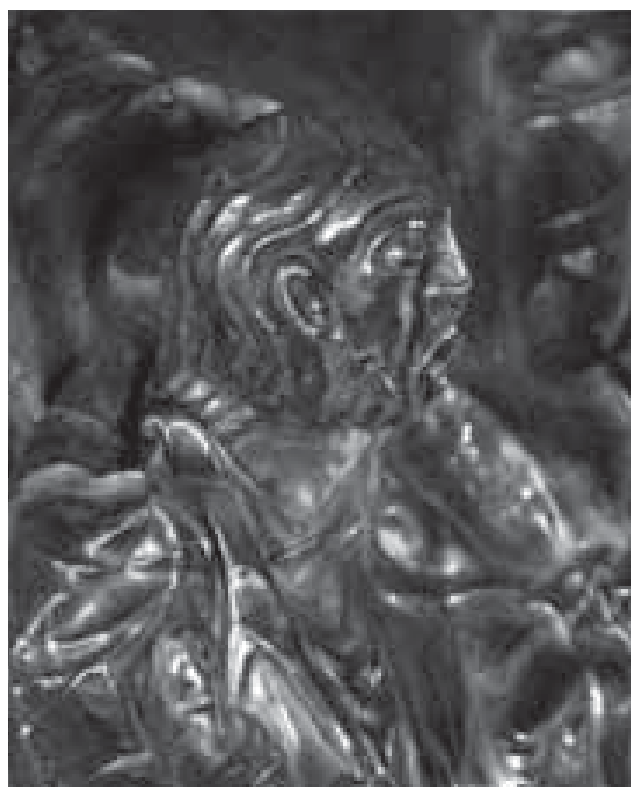

Fig. 7b. Detalle, Grande Chasse de Sion (con el permiso del Musée de l'Eveché, Sion).

${ }^{29}$ ¿Habría sido igualmente por voluntad de Constanza que su viudo donó San Salvador de Nogal, monasterium cum omnibus uillis et ereditatibus siue possessionibus suis sicut eum obtinuit uxor mea usque ad obitu eius, al monasterio de Sahagún? Documento publicado en GamBra, Alfonso VI, pp. 322-328. 
su capilla [por lo que se entienden los elementos portátiles de la misa] y con un misal y un breviario", ninguno de los cuáles han llegado a nuestros días ${ }^{30}$. Una noticia copiada en el Beato de Valcavado hace constar por lo menos de una anterior dádiva de orfebrería por parte de la infanta Elvira, una cruz de plata que había mandado hacer para el mismo monasterio. Pero el documento se escribe en 1116, el momento en el que su sobrina, la reina Urraca, la manda fundir para con los nueve marcos de plata pagar el precio de un caballo ${ }^{31}$. Con este breve informe se resume la historia de buena parte de la orfebrería medieval: la misma materia preciosa conducía muchas veces a la destrucción y reutilización por los mandatarios, sean laicos o religiosos.

Las ofrendas de alta categoría como los crucifijos obsequiados a iglesias poderosas mantenían la presencia de las donantes ante los ojos no solo de obispos, abades y abadesas sino también del público que acudía a esos templos. Se recoge la fama de generosidad que tales donaciones otorgaban a la infanta Urraca en la conocida alabanza póstuma con que la encomió el cronista de la mal llamada Historia Silense (ca. 1109-1120):

Despreciadas las carnales uniones y los perecederos vestidos maritales, por fuera bajo hábito laical mas por dentro con observancia monástica, tomó por esposo verdadero a Cristo y en todo tiempo de su vida practicó su deseado ejercicio de adornar los sacros altares y las vestiduras sacerdotales con oro, plata, y piedras preciosas ${ }^{32}$.

Además de esta visión retrospectiva y casi hagiográfica de la infanta, los documentos indican que su mecenazgo se extendía a asuntos mundanos y a la entrega de tejidos suntuosos de los que apenas han llegado a nuestros días. En el año 1071 el rey entregó a su hermana varias villas para que quedaran bajo su dominio, eximiéndolas de la obligación de pagar el tributo real. Por su parte, Alfonso recibió de ella una "adorra", una fastuosa túnica tejida de oro. El valor de la vestimenta se cuantificaba en dos mil methtecales de oro ${ }^{33}$. No se puede identificar con seguridad esta tela, pero el Arca de San Isidoro está forrada con un bordado dorado (ver fig. 6), materia cuya

30 Mea arca cum tota sua capella et cum misale et uno obreuiariu, MARTín LóPEZ, Patrimonio cultural de San Isidoro, pp. 34-36. El testamento ha sido estudiado recientemente por G. MARTIN, "Le testament d'Elvire (Tábara, 1099)", e-Spania, 5 (junio 2008), http://e-spania.revues.org/index12303.html (accedido julio 2009). Trad. "El testamento de Elvira (Tábara, 1099)", Mujeres y poderes en la España medieval, Alcalá de Henares, 2011, pp. 19-44.

${ }^{31}$ Mandauit regina domna Urraca desfacere illa crucem de Ualle Kauato, quam fecerat sua tia infante domna Geluira. Leuauit illa regina inde VIIII marcos de plata. Et dedit inde a Petro Pelagiz ... por uno kauallo, publicado en RuIz Albi, La reina doña Urraca, p. 483. El documento aparece escrito en los primeros folios del Beato de Valcavado, J.M. Ruiz Asencio (ed.), El Beato de Valcavado: facsímil y estudios, Valladolid, 1993.

32 Spretis carnalibus copulis periturisque mariti indumentis, de foris sub laycaly habitu, sed intrinsecus sub monachali obseruatione, Christo uero sponso inhesit, ac omni vite sue tempore in ornandis auro argentoue pretiosisque gemmis sacris altaribus sacerdotalibusque vestimentis desideratum exercitium peregit: J. PÉREZ De Urbel y A. GonzÁlez Ruiz-Zorrilla, (eds.), Historia Silense. Edición crítica e introducción, Madrid, 1959, pp. 122-123. Traducción al castellano por M. GómEz Moreno, Introducción a la Historia Silense con versión castellana de la misma y de la crónica de Sampiro, Madrid, 1921, p. LXXI. Estudio y traducción al inglés por S. Barton y R. Fletcher, The World of El Cid: Chronicles of the Spanish Reconquest, Manchester, 2000, pp. 9-64.

33 Et pro confirmandam igitur hanc scriptura accipio de uos una adorra auro texta qui fuit empta en duos mille methtecales de auro, publicado en GamBra, Alfonso VI, pp. 16-18. 
supervivencia es aún más complicada que la de las cruces plateadas, sobre todo si aquella se hacía con hilo de oro. Sin embargo son muy frecuentes las referencias a tejidos dorados en la literatura medieval que ayudan a comprender el significado de la indumentaria en la Edad Media. Es fácil que esta adorra fuera de fabricación andalusí porque de allí procedían los textiles de mayor prestigio en esos momentos ${ }^{34}$. Con un atuendo de esta índole, se dio una señal clara de que el rey, apoyado por su hermana primogénita, no se resignaba a controlar una parte del territorio de su padre sino que pretendía más, reto que obtuvo poco después con la muerte de su hermano Sancho en 1072 y el encarcelamiento del joven García un año después ${ }^{35}$.

Como contrapartida a su apoyo político y su desembolso económico, la infanta ganó del rey una amplificación de su propio dominio territorial. Se ve con precisión la potencia temporal de Urraca a través de un documento de 1070, conservado en la catedral de León, en el cuál María Fernández dona a domna mea infante domna Urraca las tierras que tiene en Coyanza. Los términos empleados eran del juramento de vasallaje en su estado puramente secular. Afirmó:

Yo María retengo [dichas tierras] durante los días de mi vida por vuestro regalo y bajo vuestro auxilio, y que vos, mientras viváis y seáis mi dómina, y siga yo en vuestro servicio, vos mantengáis vuestra protección sobre mi y me ayudáis contra todos los hombres y me vengáis, de la misma manera que yo me mantengo fiel a vos ${ }^{36}$.

Esta faceta de las infantas de regir en asuntos laicos no ha recibido suficiente atención por parte de los estudiosos que suelen centrarse más en su fama cronística como mujeres piadosas ${ }^{37}$. Sin embargo la misma doble naturaleza de gobernar tanto

34 Ver el excelente trabajo de M.J. Feliciano, "Muslim Shrouds for Christian Kings? A Reassessment of Andalusi Textiles in Thirteenth-Century Castilian Life and Ritual", Under the Influence: Questioning the Comparative in Medieval Castile, eds. C. Robinson, L. Rouni, Leiden, 2005, pp. 100-131. Sobre el prestigio de textiles de manufactura islámica dentro del mundo cristiano, ver los estudios en E.J. BuRns (ed.), Medieval Fabrications: Dress, Textiles, Clothwork, and Other Cultural Imaginings, Nueva York, 2004, especialmente J. SNYDER, "Cloth from the Promised Land: Appropriated Islamic Tiraz in Twelfth-Century French Sculpture", pp. 147-164 y S. KinoshitA, "Almería Silk and the French Feudal Imaginary: Toward a 'Material' History of the Medieval Mediterranean”, pp. 165-176. También O.R. Constable, Trade and Traders in Muslim Spain: The Commercial Realignment of the Iberian Peninsula, 900-1500, Cambridge, 1994; M. MARín (ed.), Tejer y vestir. De la antigüedad al islam, Madrid, 2002; J.L. SEnRa Gabriel y GalÁn, "Dos telas islámicas encontradas en el monasterio de San Zoilo de Carrión de los Condes", Goya: Revista de arte 203 (2004), pp. 332-340; E.J. BuRNS, "Saracen Silk and the Virgin's Chemise: Cultural Crossings in Cloth", Speculum 81 (2006), pp. 365-397.

35 Feliciano, "Muslim Shrouds", p. 105, cita the use of high-end textiles and costume as life-long monetary investments and appropriate symbols of their authority. Andalusi textiles made of silk threads, wrapped in gold, colored in expensive trade dyes and woven by the most skilled hands, of whatever religious creed, were, indeed, the most decorous vestments with which to assert Castilian monarchic grandeur and cultural legitimacy. Aunque el estudio de Feliciano se centra en el siglo XIII, conclusiones como esta son compatibles con el reinado de Alfonso VI.

${ }^{36}$ Ut aueat ego Maria illum in diebus uite mee de uestro dato et sub uestro auxilio, ut tamdiu uos uiuens fueritis domna mea que sedeat ego in uestro seruitio et uos que sedeat uestra mercede super me et adiutetis me super totos omines et uindicetis me quomodo ego in uos aueo fiducia, publicado en J.M. RUIZ AsENCIO, Colección documental del archivo de la Catedral de León (775-1230), vol. 4 (1032-1109), León, 1990, pp. 415-16. Agradezco la ayuda de Graham Edwards con la traducción.

37 Aportaciones interesantes en A. ViÑAYo GonZÁLEZ, «Reinas e Infantas de León, abadesas y monjas del monasterio de San Pelayo y de San Isidoro,» Semana de historia del monacato cántabro-astur-leonés, Monas- 
en lo profano como en lo sagrado se constata en el referido testamento de la infanta Elvira, hermana del rey. Escrito hacia 1099, año de su muerte, en él la infanta dispone de extensas propiedades a la vez que manda "a todos mis vasallos todos mis atuendos, caballos, lorigas, escudos y espadas que tenían de mi (...) y mando a todas mi vasallas mis mulas que tienen de mi" ${ }^{38}$. También dispone de caballos y potros para las personas criadas por ella más ganado, pan y vino para sus gentes de menor rango. A partir de este documento se desvelan las actuaciones de una gran señora con corte propia y amplias tierras, con un buen número de personas subordinadas y bien suministradas por ella pero sorprendentemente pocas posesiones de lujo. ¿Sería que prefirió gastar sus ganancias en cosas prácticas como caballos, armas, bueyes y alimentos que en objetos preciosos? Aunque parezca probable que la propia personalidad de cada donante debía haber influido en su mecenazgo, es un tema que los investigadores solo pueden sugerir con mucha cautela.

Si la documentación no deja lugar a duda sobre la autoridad que las infantas Urraca y Elvira ejercieron a través del mecenazgo, tampoco permite cuestionar la de una de las mujeres del rey, Constanza de Borgoña (ob. 1093). Viuda del conde de Chalon-sur-Saone y sobrina del Abad Hugo de Cluny, fue la segunda esposa de Alfonso VI ${ }^{39}$. Reinó a su lado durante unos catorce años (1079-1093), más que ninguna otra de sus mujeres y a lo largo de su vida hay indicaciones de que mantenía vivos los contactos con su patria. Además de la probable promoción de los enlaces de sus parientes Raimundo y Enrique con su hija Urraca y su hijastra Teresa $^{40}$, Constanza escribió una carta a Adelelmo (abad de la Chaise-Dieu, Clermont, más tarde conocido como San Lesmes) que se ha conservado dentro de la

terio de San Pelayo/Oviedo, 1982, pp. 123-135; M.I. Pérez De Tudela y Velasco, "El papel de las hermanas de Alfonso VI en la vida política y en las actividades de la corte", Estudios sobre Alfonso VI y la reconquista de Toledo (Actas del II Congreso internacional de estudios mozárabes, Toledo, 20-26 Mayo 1985), vol. II, Toledo, 1988, pp. 163-180; R. WALKER, "Sancha, Urraca and Elvira: The Virtues and Vices of Spanish Royal Women 'Dedicated to God"”, Reading Medieval Studies 24 (1998), pp. 113-138; A.I. Cerrada JimÉnez, "Tres generaciones de mujeres en el poder: Urraca de Zamora, Urraca de Castilla, Teresa de Portugal y doña Sancha", Las mujeres y el poder: representaciones y prácticas de vida, (coord. C. SEGURA Graíño, A.I. CERRADA JiméneZ), Madrid, 2000, pp. 99-106; J.M. Mínguez FernándeZ, "La infanta Urraca: su personalidad a través de la historia y de la leyenda", Anuario del Instituto de Estudios Zamoranos Florián de Ocampo 18 (2001), pp. 371-384; F.L. CoRRAL, "La infanta Urraca Fernández, prolis imperatoris Fredenandi et soror regis", La Península en la Edad Media, treinta años después. Estudios dedicados a José-Luis Martín, eds. J.M. Mínguez Fernández, G. del Ser Quijano, Salamanca, 2006, pp. 201-218.

${ }^{38}$ A totos meos uasallos totos meos atondos cauallos luricas scutos et espatas que de me tenebant ... et mando a totas meas vasallas meas mulas que de me tenent: MARTín LóPEZ, Patrimonio cultural de San Isidoro, pp. 34-36.

${ }^{39}$ Hermana del duque Eudes de Borgoña, sus padres eran Roberto, duque de Borgoña y Hermengarda, duquesa de Semur, según E. Flórez, Memorias de las reinas católicas de España, 2 vols., Madrid, 1761 (facs. ed., 1964), p. 314. Ver también J.M. Canal Sánchez-PAgín, "Jimena Muñoz, amiga de Alfonso VI,” Anuario de estudios medievales 21 (1991), pp. 11-40, esp. 15; J. DE SAlAZAR y AchA, "Contribución al estudio del reinado de Alfonso VI de Castilla: algunas aclaraciones sobre su política matrimonial", Anales de la Real Academia Matritense de Heráldica y Genealogía, 2 (1992-1993), pp. 299-336.

${ }^{40}$ B.F. Reilly, "Count Raimundo of Burgundy and French Influence in León-Castilla," Church, State, Vellum, and Stone: Essays on Medieval Spain in Honor of John Williams, eds. T. Martin y J. A. Harris, Leiden, 2005, pp. 85-109. 
vita del santo. En la carta, la reina pidió que Adelelmo fuera a reunirse con ella en España, lamentándose de que en su nueva tierra se encontraba "aislada por los Pirineos como en una esquina del mundo, lejos del resto de los fieles, en donde apenas nos llega la doctrina apostólica y por eso aquí se siguen varias liturgias" $(\text { legibus })^{41}$. En 1091 Adelelmo y el monasterio de Chaise-Dieu recibieron de Alfonso y Constanza un monasterio en Burgos cuyas lindes eran fronterizas con las del propio palacio real ${ }^{42}$.

Aunque no contamos con el testamento de la reina, quizá se pueda vislumbrar algo de su mecenazgo arquitectónico a través de las donaciones que hizo el rey cuando enviudó en 1093. Alfonso ofreció al monasterio de Sahagún el palacio que la reina había mandado construir en su entorno. En la carta, constan varios elementos del palacio, entre ellos un baño, un molino y una capilla palatina dedicada a Santa María Magdalena. Dos veces el documento repite que la protagonista en este sitio, tan asociado con Alfonso VI, no ha sido el rey sino su consorte: dice "los palacios que mi mujer Constanza fabricó" y "el baño que mi mujer, ella misma (ipsamet), construyó cerca de los palacios" "43. Tampoco titubea el cronista anónimo de Sahagún: al contrario, hace doble alarde de su mecenazgo al citar el palacio, la iglesia y el baño que "a su costa e propia mesión avía hedificado" para luego reiterar "el palacio, como ya diximos, la reina donna Costança avía hedificado e aparejado a uso de los huéspedes, abastado de muchas alhaxas e otras cosas neçesarias" ${ }^{\prime 4}$. Tanta insistencia indica la autoridad de Constanza y nos anima a especular sobre el estilo arquitectónico en el que podría haberse construido este complejo palaciego, probablemente dentro de las tradiciones constructivas ultrapirenaicas. Incluso es posible que de territorios francos llegaran los canteros y escultores que trabajaban en un lenguaje visual que hoy denominamos Románico. Más allá de la carta en la que llamaba a San Lesmes, está documentado el gran aumento de condes, obispos y abades francos en León-Castilla durante los años en los que Constanza compartió el trono con Alfonso. Sin embargo, es mucho más difícil rastrear las huellas de las personas como canteros que no pertenecían a la élite de la sociedad medieval.

Ante la falta absoluta de restos del palacio de Constanza sería muy arriesgado afirmar nada sobre la procedencia de los constructores. No obstante, la presencia

${ }^{41}$ Ad nos autem Pyrenaeis montibus interjectis quasi ceteris a fidelibus longius remotos \& in angulo terrae positos, apostolica vix unquam doctrina perveniat \& ideo variis apud nos legibus vivitur. Et quia post alios discipulos ad exemplum vitae hominum missus es in terram \& maxime quia in partibus ubi habitas, plures sunt qui bene ceteros possint instruere; mandamus \& obsecramus te, ut misertus nostri in Hispaniam venias ad nos, publicado en E. Flórez (ed.), “Adelelmi Vita,” España Sagrada XXVII, 1772, p. 857 (seg. ed. 1824, p. 450). Cit. R. Menéndez Pidal, La España del Cid, 2 vols., Madrid, 1929 (reed. 1969), vol. 1, pp. 243-244. Ver también la edición facsímil del texto del siglo XIV, R. SÁnchez Domingo, Vita Adelelmi, Vida de San Lesmes, Burgos, 2004.

42 Publicado en Gambra, Alfonso VI, pp. 300-306.

43 Ibid., pp. 328-330: (...) illos palacios quos ipsa ead. uxor mea Constancia regina fabricauit in eodem loco, prope aulam beatorum martyrum Sanctorum Facundi et Primitiui; et illam ecclesiam uocabulo Sancte Marie Magdalene, quam in eodem palacio dedicauerunt; etiam et illud balneum quod ipsamet uxor mea composuit prope illos palacios, simul cum uno molino in eodem loco fabricato.

44 Ubieto Arteta (ed.), Crónicas anónimas de Sahagún, pp. 23 y 35. 
coetánea de otro palacio en León de fábrica románica con claras afinidades ultrapirenaicas nos incita a sugerir con suma cautela que también hubiera podido trabajar un taller franco en Sahagún. En el llamado Panteón de San Isidoro se constata la obra de varios escultores, entre ellos uno que produjo capiteles con conexiones directas con la fase constructiva inicial de Saint-Sernin de Toulouse ${ }^{45}$. Desde la publicación de John Williams en 1973, la mayoría de los especialistas suelen atribuir este pequeño edificio al mecenazgo de la infanta Urraca hacia $1080^{46}$. Según nuestra teoría, ella pudo haber contratado a los canteros a partir de la construcción contemporánea del palacio de su cuñada en Sahagún. Así se explicaría la llegada del románico a León, no ex nihilo sino por vía de unos individuos - los canteros y las mecenas - unos con el conocimiento de cómo se construía en tierras lejanas y otras con los recursos para realizar la nueva arquitectura. Tal hipótesis basada en los lazos humanos solo podría convertirse en algo más sólido si se procediera a excavar en Sahagún, planteamiento que lamentablemente no se considera en este momento.

La estructura leonesa de dos plantas, cuya zona inferior se ha denominado desde finales del siglo XVII el Panteón de los Reyes ${ }^{47}$, fue elevada a poniente de la capilla palatina que había sido construida hacia mediados del siglo XI por los padres de Alfonso VI (fig. 8). La nueva construcción se adaptaba a las dimensiones de la iglesia neoasturiana a la vez que se desvinculó totalmente de ella en el lenguaje arquitectónico-escultórico ${ }^{48}$. En la planta superior hay dos estancias palaciegas ${ }^{49}$. La más grande linda con la iglesia y en su origen se abría a la nave central por una gran puerta en forma de arco de herradura. A la apertura suele llamársele ventana pero las exageradas proporciones - cuatro metros de altura y casi tres de anchura- dejan claro que fue una puerta. Además, antes de la restauración de principios del siglo XX, debajo de este vano se veían aún dos ménsulas que soportaban una

45 T. Lyman, "The Sculpture Programme of the Porte des Comtes Master at Saint-Sernin in Toulouse", Journal of the Warburg and Courtauld Institutes 34 (1971), pp. 12-39; M. DuRLIAT, La sculpture romane de la route de Saint-Jacques. De Conques à Compostelle, Mont-de-Marsan, 1990, pp. 100-103; Q. CAZES y D. CAZES, Saint-Sernin de Toulouse. De Saturnin au chef-d'oeuvre del'art roman, Graulhet, 2008.

46 J.W. Williams, "San Isidoro in León: Evidence for a New History," Art Bulletin 55 (1973), pp. 171184. Para la opinión que asocia el Panteón con el mecenazgo de Fernando y Sancha, ver I.G. BANGO ToRVISo, "El espacio para enterramientos privilegiados en la arquitectura medieval española", Anuario del Departamento de Historia y Teoría del Arte, Universidad Autónoma de Madrid 4 (1992), pp. 93-132; E. FERNÁNDEZ GonZÁlEz, "Reflexiones sobre la evolución hacia el románico de las fórmulas artísticas altomedievales, en el ámbito astur-leonés, de la undécima centuria", Hispaniens norden, pp. 48-72; F. SEEHAUSEN, "Wege zum Heil - Betrachterlenkung durch Architektur, Skulptur und Bild im Panteón de los Reyes in León”, kunsttexte. de, E-Journal für Kunst- und Bildgeschichte 4, 2009 (acceso feb. 2010).

47 J.J. Martín GonzÁlez, "El panteón real de San Isidoro. Dos proyectos fracasados de reforma y un reconocimiento de sus restos", Boletín de la Sociedad española de Excursiones 54 (1950), 157-66; M.D. CAmpos SÁnchez-Bordona, "Los proyectos de nueva construcción del Panteón Real de San Isidoro de León durante la Monarquía de los Austria”, De Arte 3 (2004), 55-84.

48 WiLliams, «San Isidoro in León."

49 Para una explicación a fondo de las pruebas que indican la sincronía de ambas plantas occidentales, ver T. Martin, "Chronicling the Iberian Palace: Written Sources and the Meanings of Medieval Christian Rulers' Residences”, Journal of Medieval Iberian Studies 2/1 (2010), pp. 109-139. 


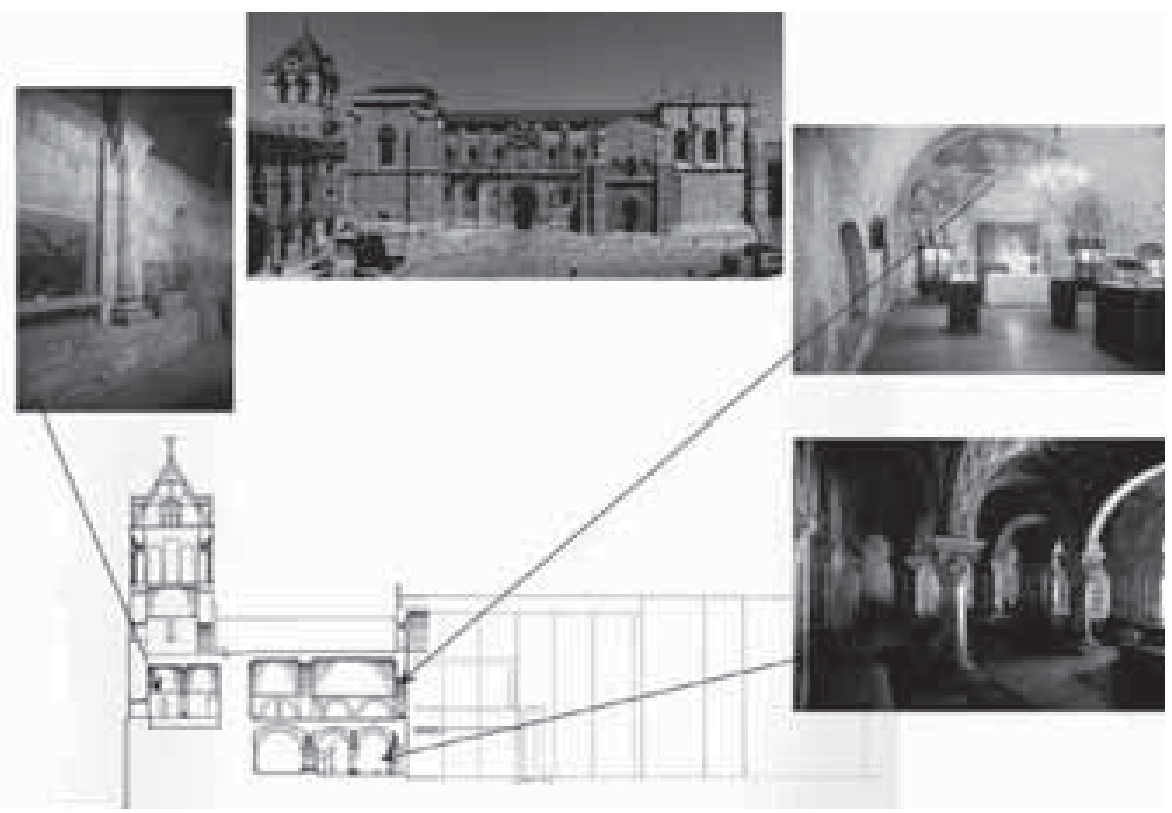

Fig. 8. Panteón y palacio, San Isidoro de León (J. Williams, T. Martin).

tribuna que a su vez se proyectaba dentro de la iglesia ${ }^{50}$. Desde este privilegiado marco la familia real habría asistido al culto y mostrado a sus súbditos.

Son varios los indicios que revelan que Panteón y estancias altas formaron parte de una sola fase constructiva fechable en tiempos de la infanta Urraca. Entre ellos, dos capiteles cuya conexión entre sí y con Saint-Sernin es indudable: uno está colocado en la pared occidental del pasillo al fondo del Panteón y otro en la puerta oriental de la tribuna superior. La iconografía muestra el castigo de los pecados a través de figuras humanas atacadas por serpientes y dragones. En el capitel del pasillo, el castigo de la lujuria se representa a través de una figura femenina de traza tosca que alza los brazos en un intento vano de apartar dos ofidios mientras que otros dos le muerden los senos (fig. 9) ${ }^{51}$. Estas culebras se cruzan encima del sexo de la mujer y pasan detrás de sus piernas para acabar rematadas con una segunda cabeza. Como bien es sabido, la escultura románica refleja con asiduidad la actitud que consideraba la lujuria, la avaricia y la soberbia los máximos pecados. Para llamar la atención de los laicos, se representaban los castigos que traerían estas transgresiones con frecuencia en las puertas de las iglesias románicas y en las zonas de acceso secular. Esta condena de la lujuria en San Isidoro está colocada en el pasillo por el que se entraba a las zonas palaciegas y se repetía en la parte alta del palacio, precisamente en el vano

\footnotetext{
50 J. Pérez Llamazares, Historia de la Real Colegiata de San Isidoro, León, León, 1927 (facs. ed. 1982), p. 338.

51 J. LeclercQ-Kadaner, "De la Terre-Mère à la Luxure", Cahiers de civilisation médiévale 18 (1975), pp. 37-43.
} 


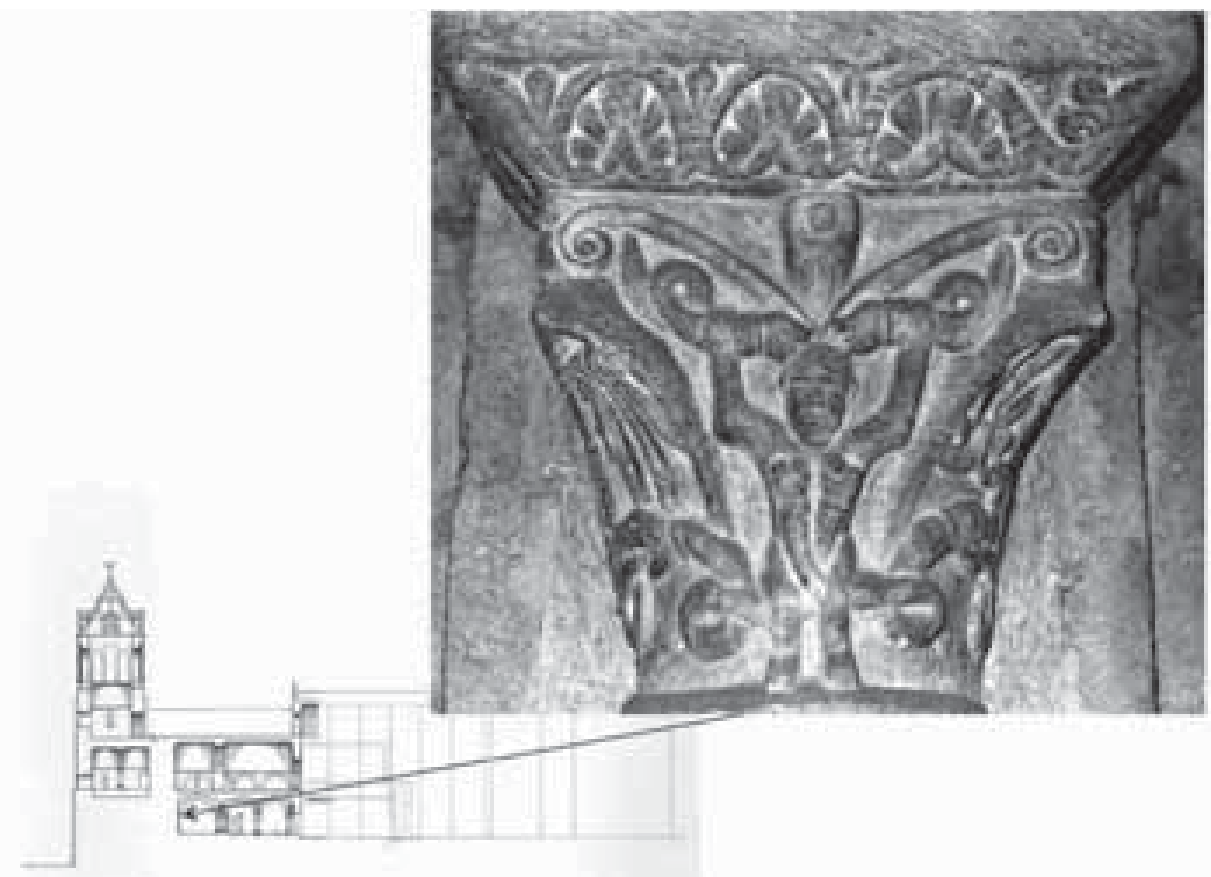

Fig. 9. Condena de lujuria, c. 1080 (J. Williams).

de la tribuna real. Aunque se ha perdido el capitel que presentaba la avaricia —un hombre arrastrado por la pesada bolsa de dinero que pende de su cuello- junto con la lujuria —otra vez una mujer mordida por culebras ${ }^{52}$ — aún se encuentra en su lugar original una figura que parece encarnar el castigo de la soberbia (fig. 10). Dos dragones de forma serpenteante se lanzan sobre la cabeza por ser la mente la fuente de la altivez. El rico atavío y calzado le identifica como un poderoso cuya soberbia terrenal le ha merecido tan terrible represalia en el más allá. La misma iconografía aparece en Saint-Sernin hacia 1080 en la Porte des Comtes, la portada del transepto sur de la basílica tolosana (fig. 11). Además de la repetición iconográfica se reconoce también el mismo estilo escultórico en los dragones de un modillón que actualmente se encuentra en el lapidario tolosano (fig. 12).

Como los especialistas vienen proponiendo desde hace tiempo, es probable que fuera la infanta Urraca la mecenas que proporcionó el impulso al arranque de las obras en la iglesia románica de San Isidoro antes de su muerte en $1101^{53}$. Segura-

52 G. Gaillard, Les débuts de la sculpture romane espagnole--León, Jaca, Compostelle, Paris, 1938, fig. 27, pl. XII.

53 Como recordaba la inscripción de su tumba confeccionada en el siglo XIII (hoy desaparecida), la infanta ampliavit ecclesiam istam. Sobre las sepulturas reales, ver A. SuÁrez GonZÁLEz, “Del pergamino a la piedra? ¿De la piedra al pergamino? (entre diplomas, obituarios y epitafios medievales de San Isidoro de León)," Anuario de estudios medievales 33/1 (2003), pp. 1-55; M.E. Martín LóPEZ, "Las inscripciones del Panteón de San 


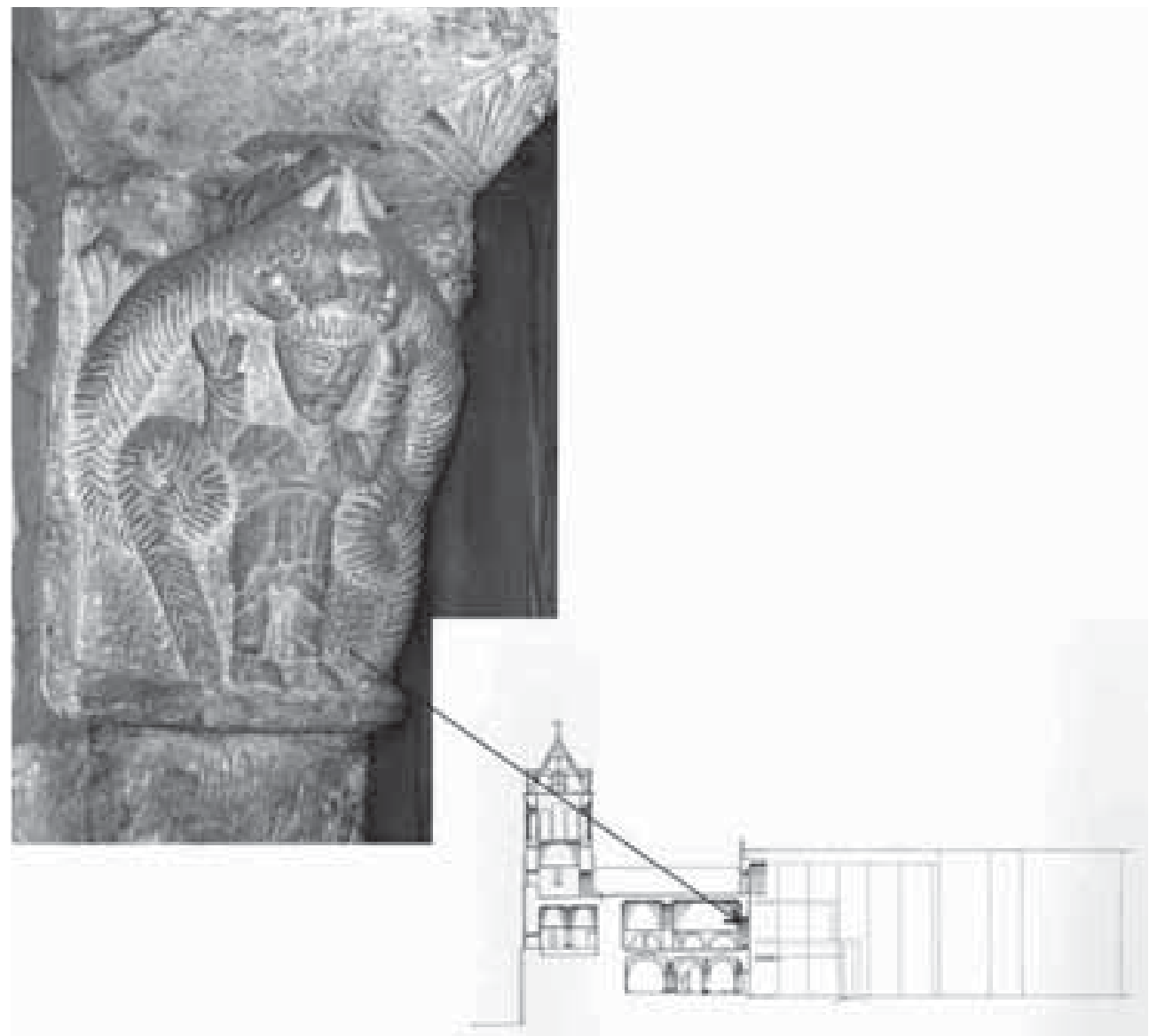

Fig. 10. Condena de soberbia (?), c. 1080 (J. Williams).

mente la infanta Elvira colaboró también, como indican las escrituras hechas en nombre de las dos hermanas ${ }^{54}$. En 1103, cuando Alfonso VI y su cuarta esposa Isabel (ob. 1107?) hicieron una donación a San Isidoro, se explicitaron las razones de

Isidoro de León: particularidades epigráficas", Escritos dedicados a José María Fernández Catón, León, II, 2004, pp. 941-972; R. SÁnchez AmEIJEIRAs, "The Eventful Life of the Royal Tombs of San Isidoro de León”, Church, State, Vellum, and Stone: Essays on Medieval Spain in Honor of John Williams, eds. T. MARTIN, J.A. Harris, Leiden, 2005, pp. 479-520; Martin, Queen as King, pp. 25-27; M.E. Prada Marcos y J.M. Vidal EnCINAs, “Arqueo-antropología del Panteón Real de San Isidoro de León”, Monarquía y sociedad en el Reino de León. De Alfonso III a Alfonso VII (Col. Fuentes y estudios de historia leonesa, 118), León, 2007, pp. 599-688; X. Dестот, Les tombeaux des familles royales de la péninsule ibérique au Moyen Age, Turnhout, 2009.

54 Ver por ejemplo el pleito sobre posesiones disputadas entre el infantazgo de San Pelayo y la catedral de León (Gambra, Alfonso VI, pp. 262-264). Se nombra primero a la infanta Urraca como domina del infantazgo pero se resuelve en acuerdo con las dos hermanas. El testamento de la infanta Elvira muestra igualmente la manera en la que las dos controlaban una parte del infantazgo de San Pelayo y ejercían el mecenazgo en San Isidoro (Martín López, ed., Patrimonio cultural de San Isidoro, pp. 34-36). 


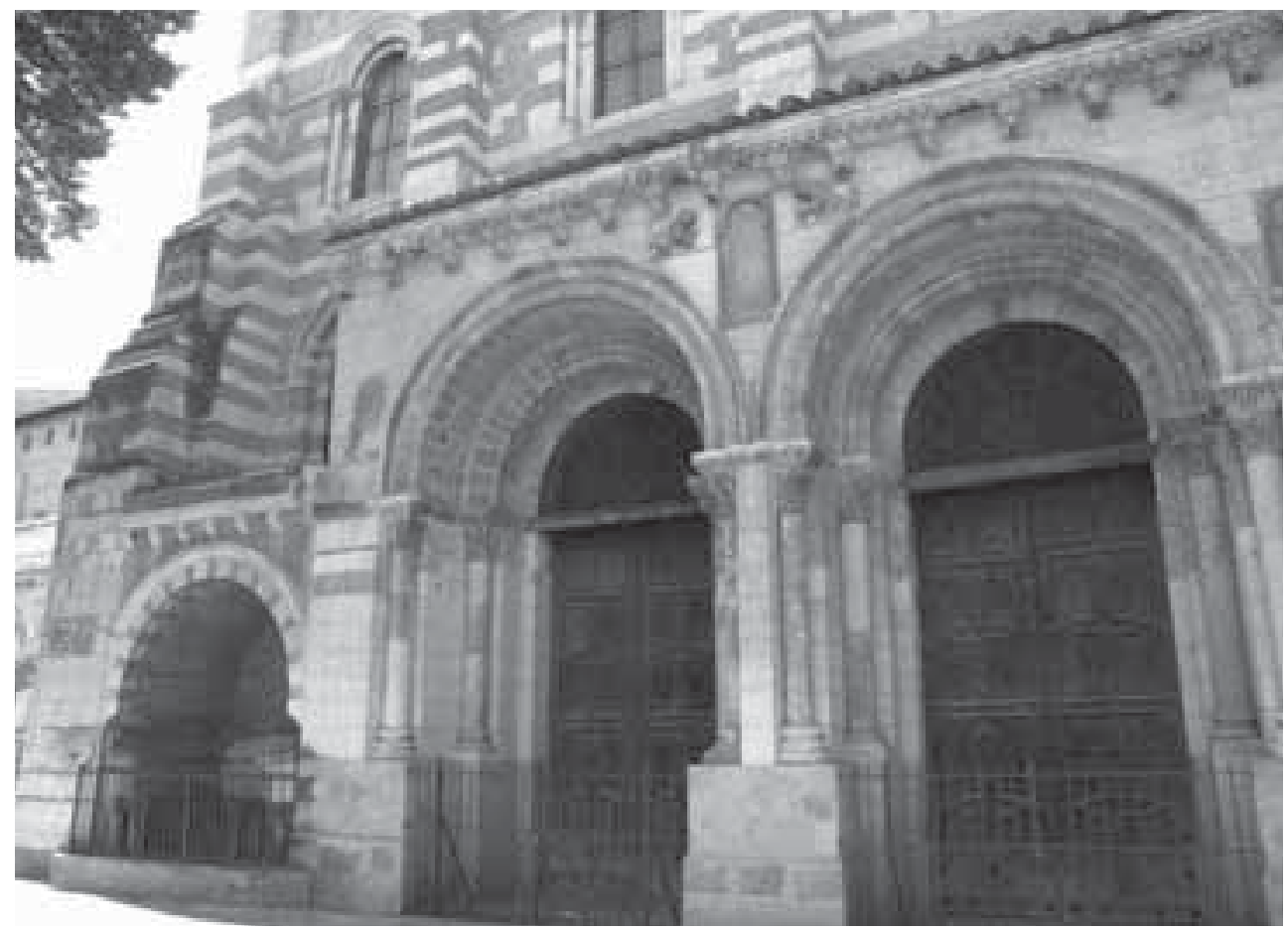

Fig. 11. Porte des Comtes, Saint-Sernin de Toulouse, c. 1080 (T. Martin).

la ofrenda con referencias a las infantas. Primero como confirmación de los anteriores instrumentos jurídicos de las dos, "de la misma manera en la que mis hermanas por sus acuerdos tanto como testamentos y otros escritos legítimos definieron y tuvieron bajo ley todas las heredades" de San Pelayo y San Isidoro ${ }^{55}$. Entre la lista de tierras que donan los monarcas se incluye medietatem de uilla Orresinos que fuit de mea germana domna Geloira et in Aradoy, Sancta Maria de uilla Ferrocinti, que similiter sua fuit. También precisa que las intenciones frustradas de Urraca le han impulsado a otorgar las confirmaciones: "por la muerte, mi hermana doña Urraca no pudo hacerlo; yo lo hago por el reposo de mi alma y de la suya y para que los fieles de Dios cuya vida mantengo y apoyo en esta era puedan orar día y noche" 56 .

El patronazgo que aportaron el monarca y sus hermanas a la iglesia real de San Isidoro se mantuvo en la siguiente generación por la primogénita y heredera de Al-

55 Gambra, Alfonso VI, pp. 451-454: sic quomodo meas germanas per suos plazos uel testamentos seu alias legitimas scripturas deffinierunt et in suo iure tenuerunt omnes supra scripti monasterii hereditates. También publicado en MarTín LóPEz, Patrimonio cultural de San Isidoro, pp. 36-38.

56 Gambra, Alfonso VI, pp. 451-454: Et quoniam istud quod ego facio superueniente morte mea germana domna Urraca facere non potuit, facio ego pro remedio animae meae atque suae et ut ipsos Dei fideles quorum uitam sustentor et subleuo in hoc seculo oratores die noctuque possim habere, ut eorum precibus munitus patrocinio beati Pelagii martiris et beati Isidori confessoris merear sotiari in celo per numquam finienda secula seculorum. También en Martín López, Patrimonio cultural de San Isidoro, pp. 36-38. 


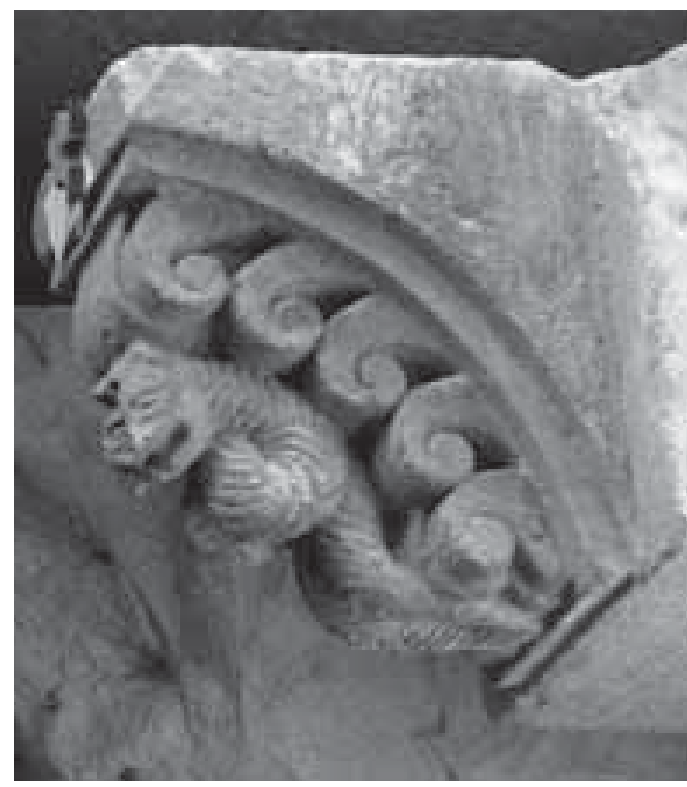

Fig. 12. Modillón, lapidario de Saint-Sernin de Toulouse, c. 1080 (T. Martin). al instalarse en San Isidoro en $1148^{60}$. Aunque más tarde se incluyeran varios miembros de la familia real en el Liber Capituli, en este primer momento fueron solo dos los que los agustinos consideraban mecenas importantes: Fernando I y la reina

57 Para la historia de la reina Urraca, ver B.F. ReIlly, The Kingdom of León-Castilla under Queen Urraca 1109-1126, Princeton, 1982 (disponible en The Library of Iberian Resources Online, http://libro.uca.edu/urraca/ urraca.htm); M.C. Pallarés y E. Portela Silva, La reina Urraca, San Sebastián, 2006; Martin, Queen as King.

58 Publicado en L. Serrano, Cartulario del monasterio de Vega, con documentos de San Pelayo y Vega de Oviedo, Madrid, 1927, pp. 37-38; Martín LóPez, Patrimonio cultural de San Isidoro, p. 39.

59 Publicado ibid., pp. 40-42; C. Monterde Albiac, Diplomatario de la reina Urraca de Castilla y León (1109-1126), Zaragoza, 1996, pp. 175-178; Ruız AlBI, La reina doña Urraca, pp. 492-494. Esta diploma tiene el detalle curioso de que la reina hace la donación una cum sorore mea Sancia pero más tarde se tachó sorore para escribir filia. El mismo cambio se produjo en las confirmaciones en dónde filia volvió a reemplazar la palabra original de sorore. Como apunta Ruız AlBi, La reina doña Urraca, p. 494, "la corrección es incorrecta". No se sabe en qué fecha se procedió a introducir a la hija de Urraca en esta donación pero sin duda fue en época moderna dado que la copia existente es del siglo XVI. Sin embargo, la tachadura tardía ha llegado a confundir a algunos especialistas que han deseado ver la actuación de la hija y no de la madre, tanto en esta donación como en todo el mecenazgo a San Isidoro. La infanta Sancha, hermana de Urraca, tuvo una presencia importante en la corte de la reina. Hasta 1120, fecha de su última confirmación, solía confirmar las cartas de Urraca antes que las otras mujeres de la familia como su hermana Elvira y su sobrina Sancha. Es probable que en ese año se casara con Rodrigo González de Lara. Ver S. BARTON, The Aristocracy in Twelfthcentury León and Castile, Cambridge, 1997, p. 292, n. 4, quién cita un documento en el que la pareja está ya casada en julio de 1122 .

60 A. SuÁrez GonzÁlez, Los códices III.1, III.2, III.3, IV y V (Biblia, Liber capituli, Misal), León, 1997; Ead., ¿Del pergamino a la piedra?”. 
Urraca. La hija de esta, la infanta Sancha, se añadió a su muerte en 1159, y un siglo después otros miembros de la familia se agregaron también al obituario. Pero en el siglo XII según los criterios de los mismos canónigos de San Isidoro, solo tres mecenas merecían recuerdo especial: Fernando, Urraca y la infanta Sancha. Según mi opinión serían el primero por haber traído las reliquias del obispo hispalense, la segunda por terminar de construir la iglesia, y la tercera por instalar a los propios agustinos.

Incluso Lucas de Tuy (ob. 1249), cuyo Liber miraculorum Sancti Isidori se escribió en 1220-1230 siendo él canónigo de San Isidoro, se vio obligado a reconocer que la reina acabó siendo una de las grandes mecenas de la colegiata:

La susodicha reina Doña Urraca, su madre, por causa de limpiar tan gran mancilla como había incurrido, y reparar tan gran daño como por su licencia y consentimiento se había hecho a la dicha iglesia de San Isidro, queriendo enmendarlo, juntamente con la muy prudente y virtuosísima infanta Doña Sancha, su hija, la cual desde su niñez afirmaba haber tomado por esposo a San Isidro, y jamás quiso casarse ni conocer varón, ambas a dos, madre e hija, deseaban y procuraban con mucho estudio y cuidado restaurar a la iglesia de San Isidro las cosas que la había sido quitadas y robadas, y con todas sus fuerzas trabajaban en hacerlo, y se ocupaban siempre en ello; y asimismo la sobredicha reina, con gran diligencia hizo juntar $\mathrm{y}$ traer de diversas partes del mundo reliquias de muchos santos y ponerlas honrada y devotamente en cajas de plata y marfil y diólas a la dicha iglesia de San Isidro, y también le dió muchas heredades y privilegios reales, y en su vida hizo hacer aparejar para sí la sepultura en la dicha iglesia con sus padres y antepasados ${ }^{61}$.

Como se sabe, hubo más de un momento constructivo en la basílica románica de San Isidoro (fig. 13 ${ }^{62}$. Hemos sugerido que pueden dividirse básicamente en uno inicial en el que la mecenas principal fuera la infanta Urraca, situado hacia 1095 a 1101, y otro hacia 1110 a 1124, bajo el mecenazgo de la reina Urraca. La elevación de la iglesia románica comenzó desde la cabecera tripartita y en la primera fase se llegaron a acabar cuatro tramos de tres naves que se habrían cubierto de madera. $\mathrm{La}$ obra culminante de la primera fase constructiva y escultórica fue la Puerta del Cordero, probablemente terminada hacia 1100 (fig. 14) ${ }^{63}$. En un estudio inédito enca-

${ }^{61}$ Biblioteca de la Real Colegiata de San Isidoro, ms. 63; J. Pérez Llamazares (ed.), Milagros de San Isidoro, León, 1947 (facs. ed. 1992), p. 48.

${ }^{62}$ La única monografía que se ha escrito sobre el conjunto arquitectónico con una explicación detallada de las fases constructivas es MARTIN, Queen as King. Recientemente otras conclusiones han sido propuestas por G. Boto Varela, "Arquitectura medieval. Configuración espacial y aptitudes funcionales", Real Colegiata de San Isidoro, pp. 51-103, y por F. SEEHAUSEN, "Baugeschichte als dynastisches Konstrukt: Die Bauphasen und ihre Interrelation mit der Kapitellskulptur von San Isidoro in León”, Hispaniens Norden im 11. Jahrhundert. Christliche Kunst im Umbruch, eds. A. Arbeiter, C. Kothe, B. Marten, Petersberg, 2009, pp. 198-209.

${ }^{63}$ S. Moralejo Álvarez, "Pour l'interpretation iconographique du portail de l'agneau a Saint-Isidore de León: les signes du zodiaque," Cahiers de Saint-Michel de Cuxa, 8 (1977), pp. 137-173 (también en Patrimonio artístico, I, pp. 111-130); J.W. Williams, "Generationes Abrahae: Reconquest Iconography in León," Gesta 16-2 (1977), pp. 3-14; versión castellana con postscriptum actualizado, "Generationes Abrahae: Iconografía de la Reconquista en León”, El tímpano románico. Imágenes, estructuras y audiencias, eds. R. SÁNchez Ameijeiras, J. L. Senra Gabriel y Galán, Santiago de Compostela, 2003, pp. 155-180; S.H. Caldwell, "Urraca of Zamora and San Isidoro in León: Fulfillment of a Legacy", Woman's Art Journal 7/1, pp. 19-25; T. 


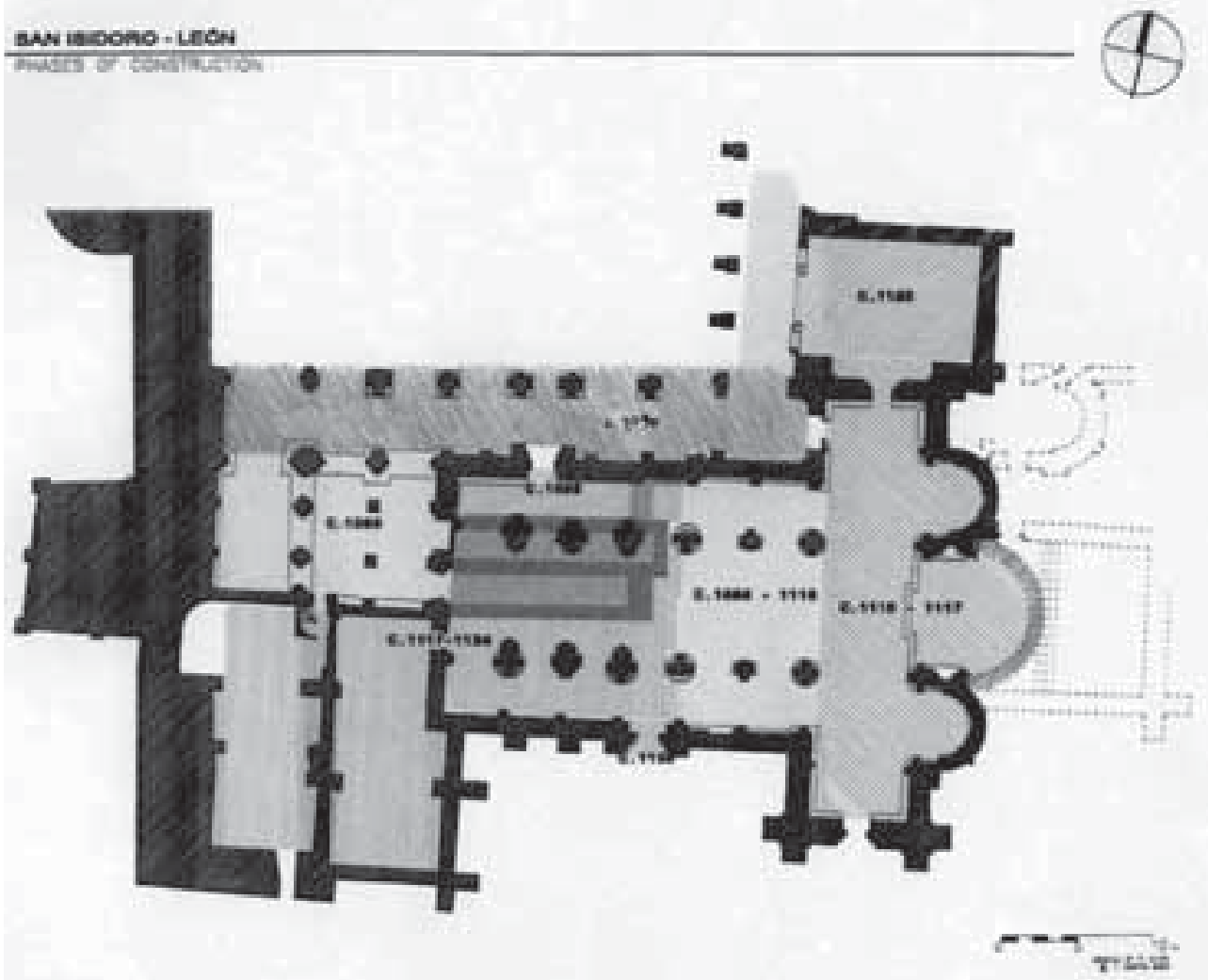

Fig. 13. Plano, San Isidoro de León (T. Martin).

minado a la restauración de la portada se han resaltado las diferentes materias que se emplearon en la escultura: mármol en la placa del Cordero junto con los ángeles y arenisca en la placa inferior del Sacrificio de Isaac. Las demás figuras en las enjutas (los santos Isidoro y Pelayo, el rey David con los músicos y el zodiaco) son de mármoles de diferentes colores. El estado de conservación en general es bastante lamentable y ha empeorado notablemente por la capa protectora con que se cubrió en una anterior restauración. Como consta en una foto de 2009 contrastada con otra del año 1970, lejos de proteger esta sustancia ha frenado la respiración natural de la piedra, llevando al desarrollo de ampollas que ahora se están quebrando (fig. 15).

En la segunda fase constructiva de la basílica románica, se constata el cambio de mano de obra tanto a partir de las marcas de cantería como del estilo escultórico ${ }^{64}$.

Martin, "Un nuevo contexto para el tímpano de la Portada del Cordero en San Isidoro de León”, El tímpano románico, pp. 181-205; PRADO-VILAR, “Lacrimae rerum”.

64 T. Martin, "Reading the Walls: Mason's Marks and the Archaeology of Architecture at San Isidoro, León”, Church, State, Vellum, and Stone, pp. 373-412. 


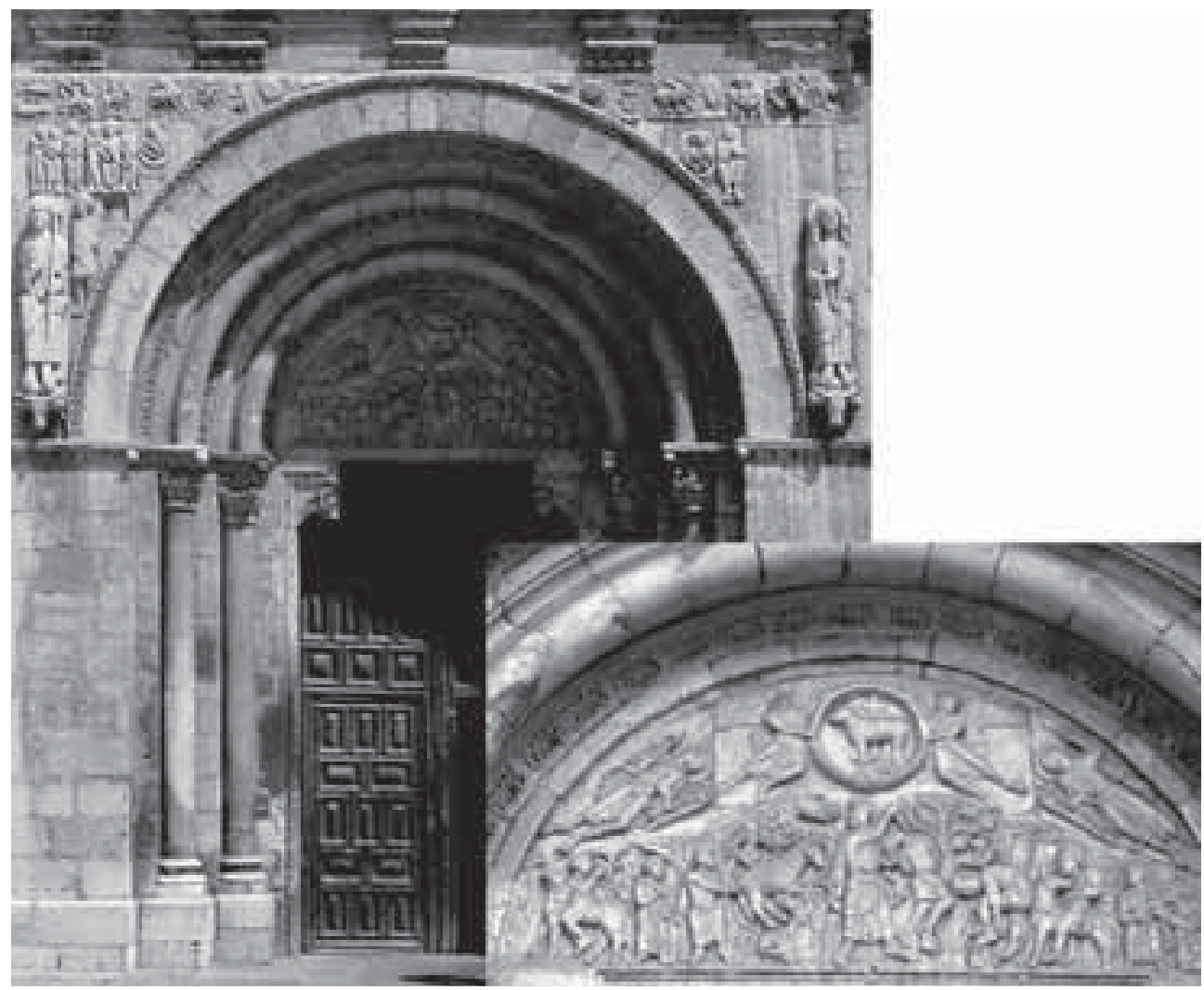

Fig. 14. Puerta del Cordero, San Isidoro de León (T. Martin).

Según nuestra teoría, bajo el mecenazgo de la reina Urraca un taller escultórico procedente de Santiago de Compostela llegaría a León hacia 1112, año en el que, como Serafín Moralejo demostró, se produjo un gran cambio en la escultura de la catedral compostelana ya que los capiteles realizados a partir de ese momento eran mucho más sencillos que los anteriores ${ }^{65}$. Según este especialista, los mejores canteros-escultores se habían marchado, dejando atrás a los miembros menos destacados del taller. Por nuestra parte, hemos defendido la hipótesis de que pudieron trasladarse a León para trabajar en San Isidoro ${ }^{66}$. Mientras que la relación entre Urraca y el obispo de Santiago rara vez fue cómoda, es factible que éste le hubiera facilitado un taller de canteros para su iglesia al igual que la reina le hizo entrega

65 S. Moralejo Álvarez, "Notas para una revisión de la obra de K. J. Conant", Kenneth John Conant, Arquitectura románica da catedral de Santiago de Compostela, Santiago de Compostela (Cambridge, Mass., 1926), pp. 221-236 (también en Patrimonio artístico, I, pp. 247-263).

66 Martin, Queen as King, pp. 115-116. Recordamos que la donación de 1110 in illo labore Sancti Ysidori por parte de Diego Alvitiz, indica que en esa década hay que ubicar una de las fases constructivas de la iglesia (ver nota 58). 

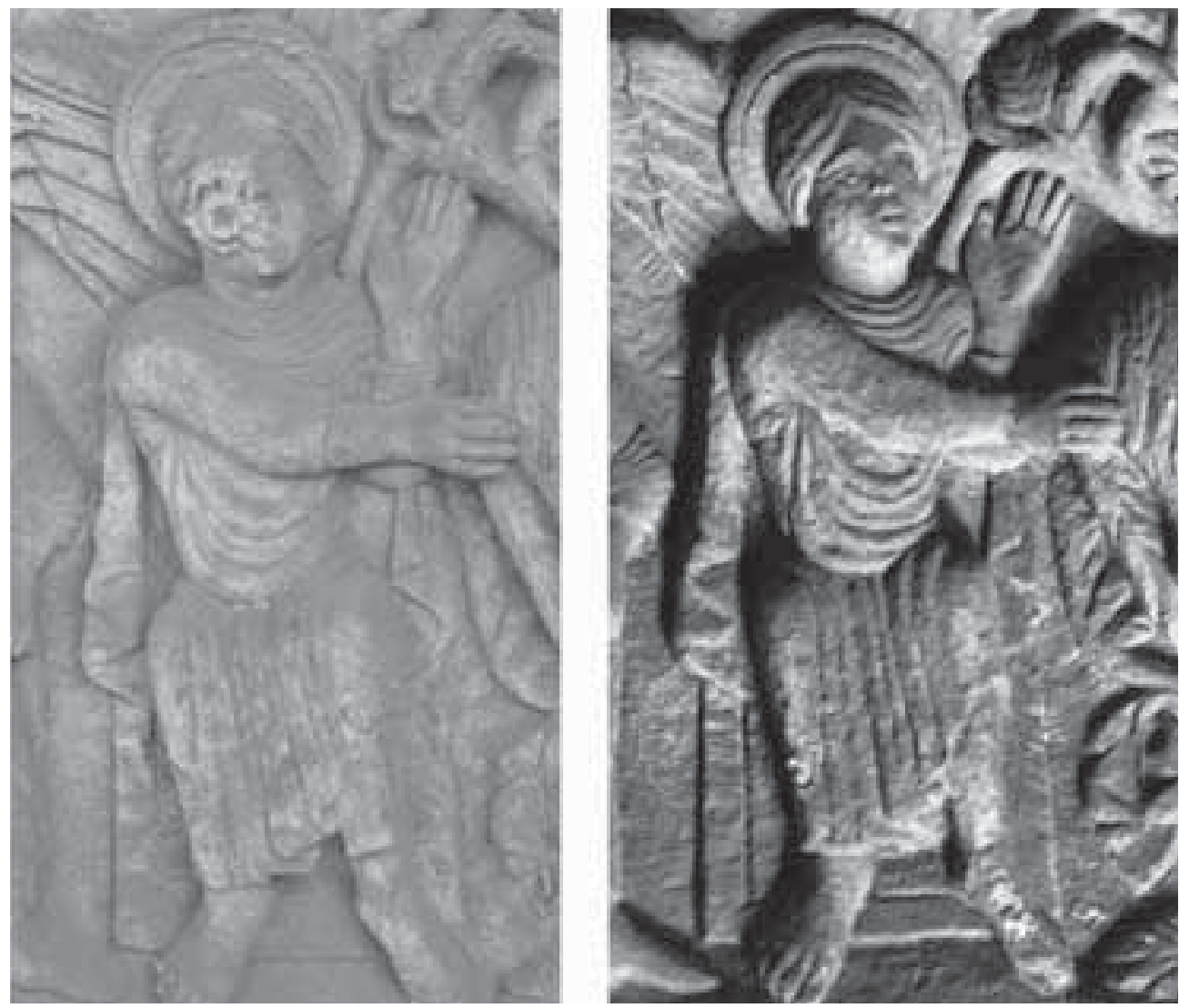

Fig. 15. Detalles, Puerta del Cordero en 2009 y 1970 (T. Martin, J. Williams).

para la catedral compostelana de un relicario de plata con un Lignum Crucis ${ }^{67} \mathrm{e}$ incluso de la misma cabeza del apóstol Santiago:

Cuando [la reina] supo que la cabeza de Santiago, que había traído el obispo Mauricio desde Jerusalén, estaba en la iglesia de San Zoilo, ella misma la sacó desde allí junto con las restantes reliquias y la llevó a León, colocándola en la iglesia de San Isidoro. Y así regaló al obispo de Santiago tan gran tesoro, a saber: la cabeza de Santiago, un trozo del sepulcro del Señor, un hueso de San Esteban y otras reliquias con un vaso de plata. ${ }^{68}$

${ }^{67}$ E. Falque Rey (ed.), Historia Compostellana, Corpus Christianorum Continuatio Mediaevalis 70, Turnhout, 1988, Liber II, 57, 34 (edición española, E. Falque Rey, ed., Historia Compostelana, Madrid, 1994, p. 409). A pesar de las quejas del obispo durante su reinado, a Urraca se le recuerda como una mecenas generosa después de la muerte cuando le insta a su hijo Alfonso VII a seguir el buen ejemplo de su padre y su madre con las donaciones a la Catedral: Tu quoque tui patris et matris et bonorum regum atque principum, qui corpora sua et animas suas personis ecclesiasticis et ecclesiis commendant, uestigia sequi et exempla imitari accurate debes, Historia Compostellana, II, 87.

${ }_{68}$ Historia Compostellana, I, 112 (ed. española, pp. 267-268): Que ut nouit caput beati Iacobi, quod M. episcopus Iherosolimis attulerat, in ecclesia sancti Zoyli esse, ipsamet illud cum ceteris reliquiis abhinc abs- 
Aunque actualmente la historiografía tradicional recuerda a Urraca sobre todo por un reinado tumultuoso, teorizamos en torno a que aumentó y remató la construcción de esta iglesia de su familia en la capital del reino con el fin de fomentar la memoria de su progenitor y para consolidar la precariedad de su posición como reina reinante. Es probable que las obras en la basílica concluyeran al final del primer cuarto del siglo XII ${ }^{69}$. Las pruebas estilísticas de la escultura se confirman a través de una sencilla inscripción con la fecha 1124 (E[RA] MCLXII), junto con una marca de cantero que se ve casi exclusivamente en la fase final de la iglesia. Hoy se encuentra empotrada en el exterior del ábside norte pero ha sido cambiada de su localización original en el muro occidental de la iglesia ${ }^{70}$.

Bajo el mecenazgo de la reina Urraca, la basílica de San Isidoro pasó de ser un edificio con techumbre de madera a un espacio con bóvedas de cañón en la nave central y de arista en las laterales (fig. 16). Dentro del cambio, también se reconcibió la cabecera, como indican los restos arqueológicos de los pilares del primer tramo que se suprimieron con el fin de crear un crucero. ${ }^{71} \mathrm{Al}$ construir el transepto, también se ampliaron los absidiolos cuyos muros exteriores se extienden más allá de los laterales norte y sur de la iglesia. El ábside central se mantuvo intacto hasta que fue reemplazado en 1513 por una estructura gótica pero la huella del original se mantuvo en el pavimento (fig. 17). En 1572, Ambrosio de Morales lo explicó así: "aunque no hay Escritura, que se tuvo cuidado

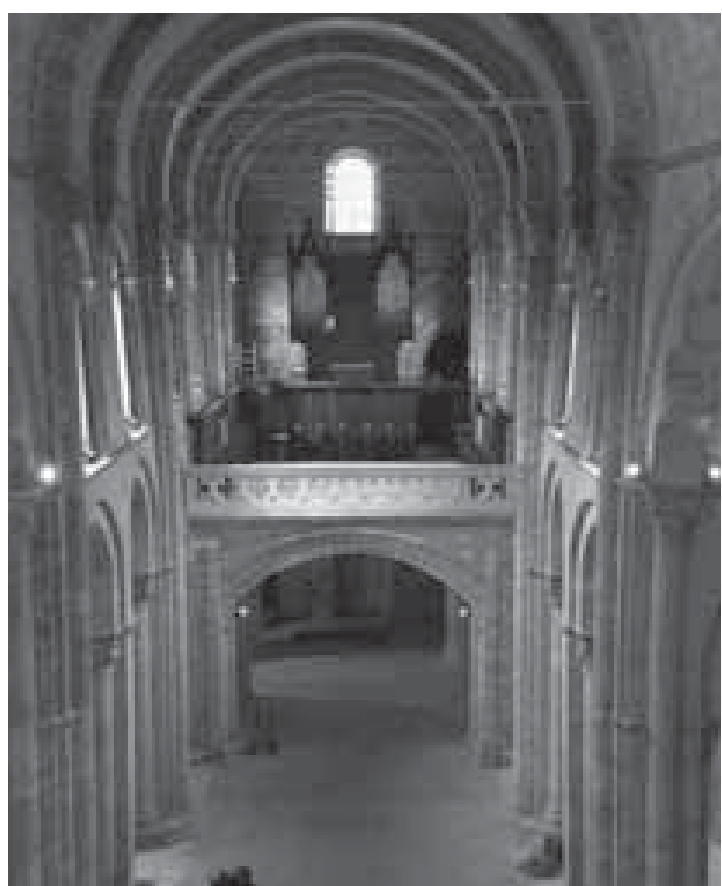

Fig. 16. Interior, San Isidoro de León (T. Martin). de conservar en las gradas y en el suelo las piedras antiguas de que manó agua milagrosamente en la muerte de los dos Reyes Fernando Primero y Alfonso Sexto, como en

traxit et asportauit Legionem collocans in ecclesia sancti Isidori. Tantum igitur thesaurum, scilicet apud beati Iacobi et frustum Dominici sepulcri et quoddam os sancti Stephani ceterasque reliquias cum uase argenteo contulit predicto beati Iacobi episcopo.

${ }^{69}$ DuRliat, La sculpture romane, p. 389.

${ }^{70}$ Martin, "Reading the Walls".

${ }^{71}$ Sobre la arqueología de la iglesia, ver J. WiLliams, "San Isidoro Exposed: The Vicissitudes of Research in Romanesque Art”, Journal of Medieval Iberian Studies, 3/1 (2011), pp. 93-116. 

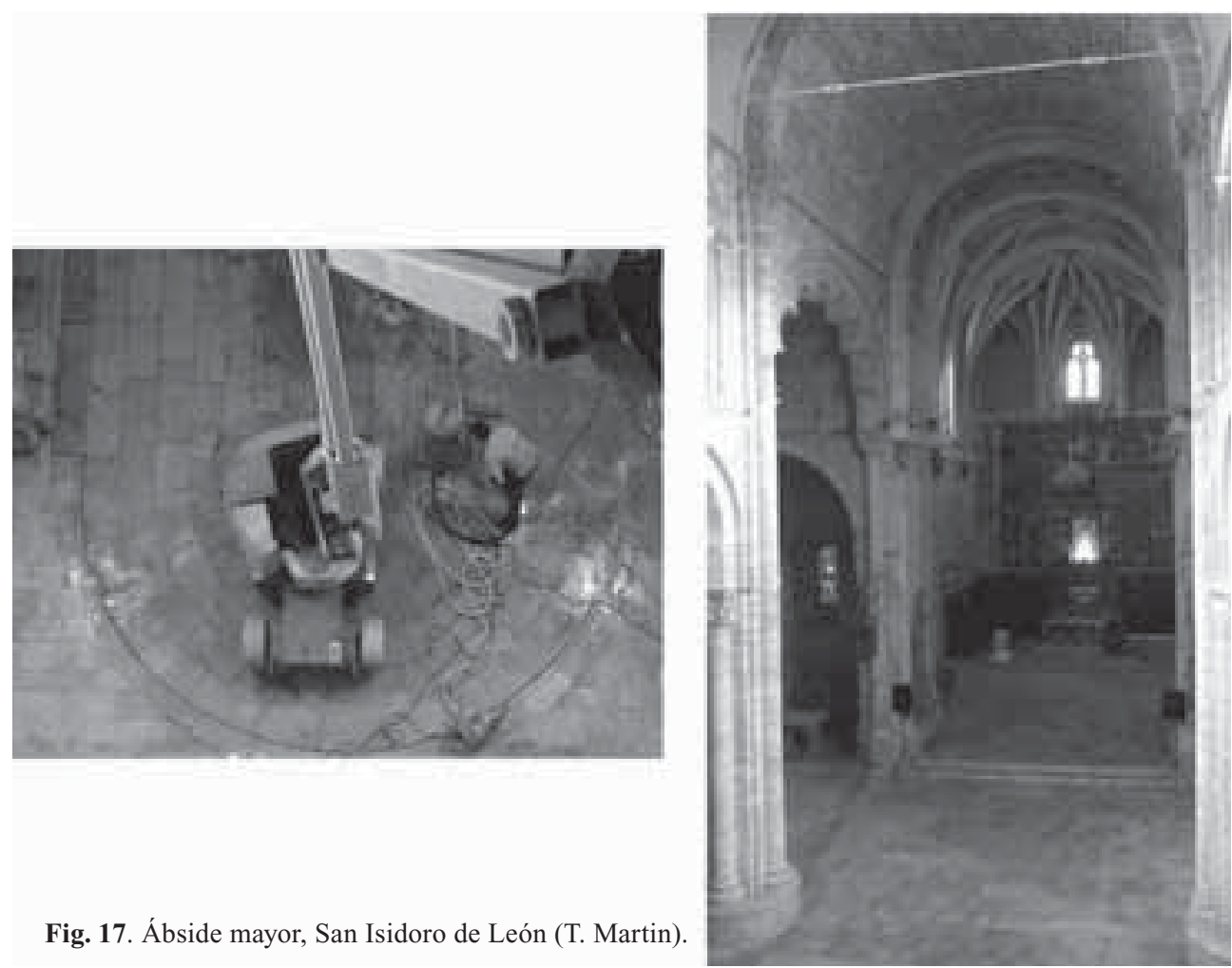

Fig. 17. Ábside mayor, San Isidoro de León (T. Martin).

nuestras Historias se cuenta"72. Afortunadamente, se conservaron también los nichos del primer ábside mayor, cuyas marcas de cantería son idénticas a las de la primera fase constructiva. La producción escultórica de este primer taller incluye varias imágenes de monstruos: uno en el exterior del ábside norte, dos en los mentados nichos y dos en la Puerta del Cordero (fig. 18). Todos aparecen en zonas de apertura, umbrales que pueden haberse concebido de fácil acceso a lo malévolo. La falta de monstruos en los pilares del interior de la iglesia lleva a deducir que estas imágenes tuvieron una función apotropaica. Sirvieron para espantar el mal que intentara penetrar en el templo o en el espacio más sagrado del ábside mayor.

Dentro de la segunda fase, la mano del taller compostelano se percibe con claridad en una Maiestas Domini en la que la figura del Cristo teofánico se dispone

72 A. De Morales, Viage por orden del Rey d. Phelipe II. a los Reynos de Leon y Galicia y Principado de Asturias, para reconocer las Reliquias de Santos, Sepulcros Reales, y Libros Manuscritos de las Cathedrales, y Monasterios, Córdoba, 1572 (facs. ed. Oviedo, 1977), p. 48. Según la Crónica del Obispo Pelayo, escrita en la primera mitad del s. XII, el milagroso manantial manó a la muerte de Alfonso VI. Crónica del Obispo Don Pelayo, ed. B. SÁnchez Alonso, Madrid, 1924, pp. 84-86; S. Barton y R. Fletcher, The World of El Cid: Chronicles of the Spanish Reconquest, Manchester, 2000, pp. 65-89. Ver también R. ALONSO, "Ploraverunt lapides et manaverunt aquam. El planto por el rey según las crónicas de los reinos occidentales hispánicos”, Politiques des émotions au Moyen Âge, eds. D. Boquet y P. Nagy, Florencia, 2010, pp. 115-148. 


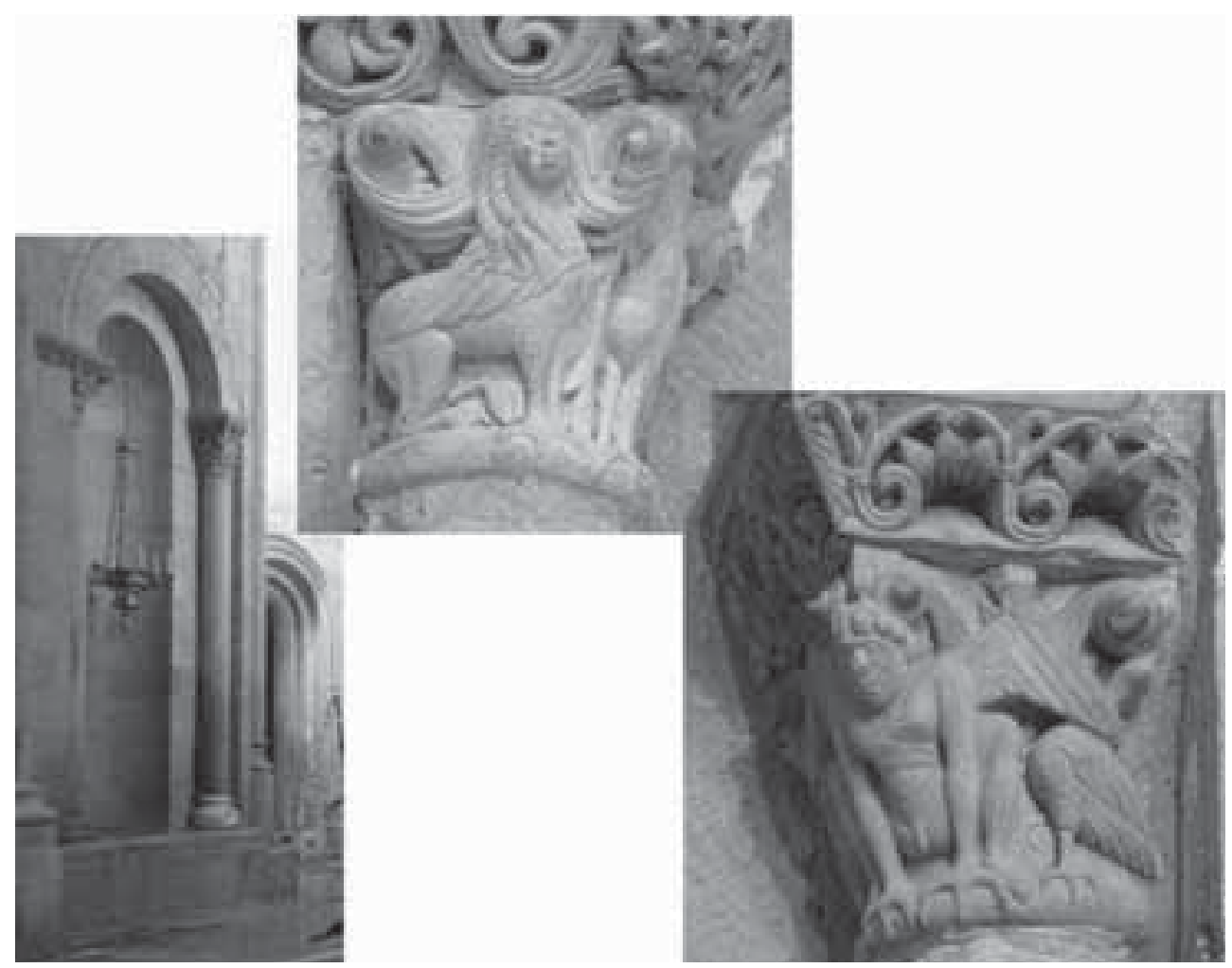

Fig. 18. Monstruos, ábside mayor, c. 1095-1100 (T. Martin).

entronizado y flanqueado por ángeles (fig. 19) ${ }^{73}$. Sostiene un gran Libro de la Vida con la mano izquierda mientras alza la derecha en actitud de bendecir. Al comenzar la inscripción en contacto con el dedo, se verbaliza el gesto: BENEDICAT NOS $\mathrm{D}$ [OMIN]US que continua al otro lado DE SEDE MAIESTATIS. Hay que reconocer la habilidad de este escultor que ha decidido invertir las primeras palabras con el fin de que el término "bendíganos" fuera inmediato al gesto parlante de bendición.

Semejante mensaje se encuentra en la inscripción que hemos reconstruido recientemente para la portada norte (fig. 20) ${ }^{74}$. Se centraba en una Maiestas Domini rodeada de los símbolos de los Evangelistas. No se conserva la frase entera pero el fragmento inscrito se podría completar como "Sentado en la cima de la fortaleza de

73 Sobre el tema de la Maiestas, ver F. Van Der Meer, Maiestas Domini: Théophanies de l'Apocalypse dans l'art chrétien, étude sur les origine d'une iconographie spéciale du Christ, Roma/Paris, 1938; Y. CHRISTE, Les grands portails romans. Etudes sur l'iconologie des théophanies romanes, Ginebra, 1969.

74 T. MARTin, "Una reconstrucción hipotética de la portada norte de la Real Colegiata de San Isidoro, León”, Archivo Español de Arte, 81, no. 324 (2008), pp. 357-378. 


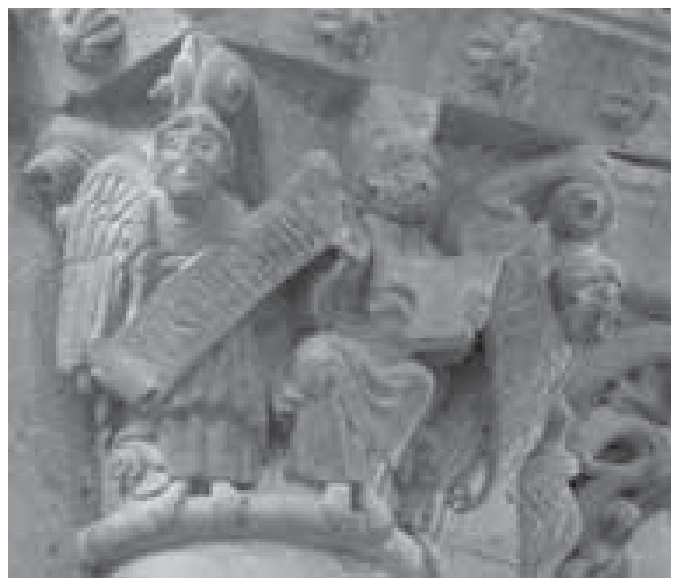

Fig. 19. Maiestas, c. 1115 (T. Martin).

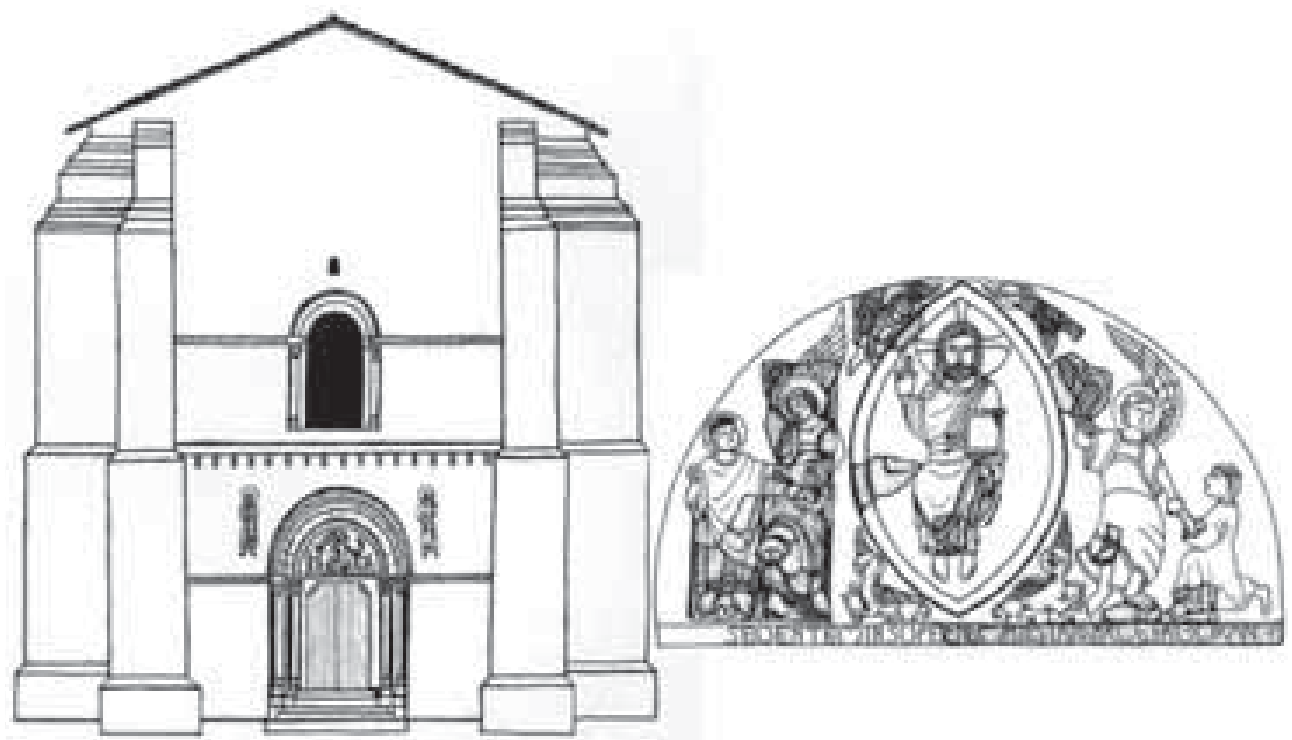

Fig. 20. Reconstrucción del tímpano norte, c. 1115 (T. Martin/A.Turner).

la Majestad, le adoran"75, frase derivada de las alabanzas de los ángeles y las bestias que rodean el trono de Dios. La figura lateral, más íntegra, es un ángel que se dirige a la derecha - hacia Cristo - a la vez que se gira hacia atrás para llevar consigo un santo. De la representación del santo al que coge del brazo, poco se puede afirmar más allá de su oficio de abad u obispo que se reconoce por el atributo del báculo que sos-

75 La fragmentaria inscripción reza [ ]NE MAIESTATIS ARCE + ADORAN[ ] Sedentem in superne maiestatis arce adorant, Isaías 6:3 y Apocalipsis 4:8-9. Agradezco a Conrad Rudolph esta sugerente posibilidad para completar la frase de la inscripción. 
tiene. ¿Sería una imagen de Isidoro, patrón de este templo ${ }^{76}$ ? En cuanto a la figura del otro extremo del tímpano, cabe la posibilidad de que representara a una persona laica asociada con San Isidoro, quizá incluso el mismo Alfonso VI. Dos tímpanos franceses del siglo XII, Saint-Georges de Mervilliers y Notre Dame de Paris, proporcionan ejemplos comparativos en los que se encuentran donantes seculares arrodillados a un lado y figuras eclesiásticas al otro ${ }^{77}$. En el centro del tímpano leonés, Cristo está entronizado en el cielo, preparado para juzgar a la humanidad al final de los días. Los que tienen derecho a acercarse son los que han seguido sus mandatos durante la vida, entre los

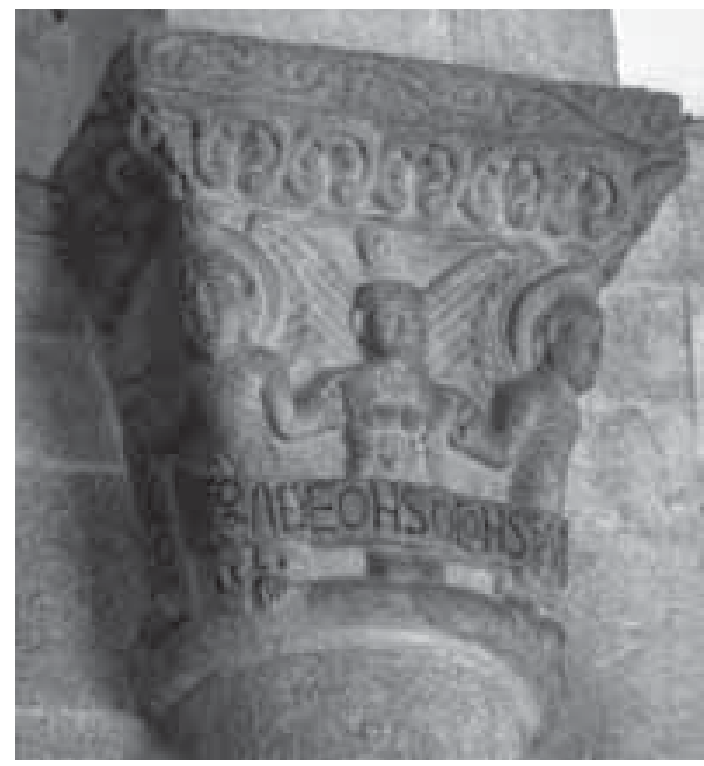

Fig. 21. Alfonso VI, Santiago de Compostela, c. 1080

(T. Martin). cuáles no habrían dudado en incluir al añorado rey Alfonso VI, tal y como en su día se había manifestado entre ángeles en el ábside mayor de la catedral de Santiago de Compostela (fig. 21). Si, como hemos sostenido, el hastial norte de San Isidoro de León se elevó dentro de la segunda fase constructiva, es posible que el tímpano hubiera servido para recordar al progenitor dentro del mecenazgo de su hija Urraca.

En fin, ¿cuáles son las conclusiones que se pueden trazar a partir de los ejemplos expuestos a lo largo de este estudio sobre las mujeres en el entorno familiar de Alfonso VI? Primero, utilizaban el arte y la arquitectura para forjar alianzas, demostrar lealtades y atar a otras personas con lazos de obligación. Dentro del marco de una sociedad en la que el acto de aceptar un presente suponía adquirir un compromiso hacía el donante, el mecenazgo fue de por sí interesado aun cuando lo impulsara la piedad.

Segundo, no se puede generalizar sobre un mecenazgo supuestamente "femenino", porque estos casos muestran grandes diferencias entre sí. Hemos seguido algunos de los pasos de las infantas Urraca y Elvira, dos mujeres solteras cuasireligiosas (rigieron el infantazgo sin ser monjas profesas) que aprovecharon su he-

76 Hace ya más de treinta años, Antonio Viñayo sugirió la posibilidad de que esta figura se identificara con San Isidoro y perteneciera a un tímpano, sin especular sobre su lugar de emplazamiento, proponiendo la ubicación del ángel en el ángulo superior izquierdo del hipotético tímpano. Ver A. ViÑayo GonZÁlez, León y Asturias (La España Románica, vol. 5), Madrid, 1982 (1979; Leon Roman, Zodiaque, 1972), p. 128.

77 Martin, "Una reconstrucción hipotética”, pp. 375-377. 
rencia para actuar con gran autonomía y autoridad. Sin embargo, el mero hecho de heredar el infantazgo no garantizaba que se gobernara como lo habían hecho estas dos. Se lee algo del fuerte carácter de las hermanas a través de los siglos en los documentos, sobre todo pleitos y acuerdos con el rey ${ }^{78}$, por contraste con las infantas de la siguiente generación. Sancha y Elvira, hijas de Alfonso VI y la reina Isabel, se denominan las dominas de San Isidoro en el mentado documento de 1110 en el que se refiere a la construcción de la iglesia ${ }^{79}$. En 1116, estas infantas confirman una donación a la catedral de León con la firma "Sancha y Elvira, hermanas de la reina y regentes del monasterio de San Pelayo", en un aparente reclamo de autoridad ${ }^{80}$. Sin embargo no quedan apenas evidencias de que estas dos hubieran dirigido el infantazgo con el mismo poder independiente de sus tías, quizá porque su hermana la reina mantuvo buena parte de la herencia para sí, quizá porque no se quedaron solteras. A diferencia de sus tías y de su sobrina Sancha (ob. 1159), figura poderosa de la siguiente generación en San Isidoro, las dos hermanas contrajeron nupcias y fueron a ejercer su mecenazgo a tierras de sus familias políticas ${ }^{81}$.

Finalmente, hay que entender el mecenazgo como un acto de creación. En las inscripciones, se suele emplear la palabra "facere" - hacer - tanto para indicar al mecenas como al artista. $\mathrm{O}$ sea, concebir, fundar y sufragar una obra de arte o arquitectura se reconocía en la Edad Media como algo que hoy equiparamos con la creatividad. Esto le concedió al o a la donante una autoridad en dos sentidos. Primero, era un claro ejercicio de poder, algo que se ha venido resaltando en la historiografía. Pero más allá de eso, un segundo sentido está inherente en la misma palabra de autoridad: el donante como "autor" de su obra. Este último resulta muy importante en el estudio de la mujer medieval porque la propia palabra "patronazgo" implica que el mecenas sea un hombre. Como bien ha notado Madeline Caviness, no existe el "matronazgo" y ser patrón es muy diferente de ser matrona ${ }^{82}$. Un ejemplo en el que se resumen los papeles activos de mecenas y artista se encuentra en la iglesia monástica de San Salvador de Nogal de las Huertas (Palencia). Las inscripciones incluyen las frases

78 Ver nota 54.

79 Serrano, Cartulario del monasterio de Vega, pp. 37-38; Martín LóPez, Patrimonio cultural de San Isidoro, p. 38-39. La donación de Diego Alvitiz se hace sub gratia reginae Urraka et illius germanae Sanciae et Geloire. Figuran estas últimas en las confirmaciones como dominas nostras.

${ }^{80}$ Sancia et Geloira eiusdem regine sororibus, domum Sancti Pelagii regentibus: J.M. FeRnández CATÓN, Colección documental del archivo de la Catedral de León (775-1230), vol. 5 (1109-1187), León, 1990, p. 52-56.

81 Sancha se casó hacia 1120 con Rodrigo González de Lara, Elvira hacia 1117 con Roger II de Sicilia. Sobre la cuestión del infantazgo y las mujeres solteras o casadas, ver P. HENRIET, "Deo votas: L'Infantado et la fonction des infantes dans la Castille et le Leon des Xe-XIIIe siècles", Au cloître et dans le mond. Femmes, hommes et sociétés (IXe-Xve siècles). Mélanges en l'honneur de Paulette L'Hermite-Leclercq, eds. P. HeNRIET, A.-M. Legras, Paris, 2000, pp. 189-203; T. Martin, "Hacia una clarificación del infantazgo en tiempos de la reina Urraca y su hija la infanta Sancha (ca. 1107-1159)", e-Spania, Revue électronique d'études hispaniques médiévales 5, June 2008, http://e-spania.revues.org/document12163.html.

82 CAviness, «Anchoress, Abbess and Queen", p. 106. 
"Elvira Sánchez hizo esto" y "Jimeno hizo y esculpió esta puerta"83. A la dama noble se le denomina en primer lugar y con nombre y patronímico; su contribución a la creación de la iglesia fue la ofrenda que posibilitó la construcción. Está seguida en importancia por Jimeno cuya participación se clarificó con un segundo verbo (fecit et sculpsit). Hoy en día, vemos una mecenas y un artista pero en la Edad Media a los dos se les consideraba los creadores del edificio.

Entonces, ¿quién fue realmente el responsable de una obra medieval, la persona que lo impulsó o la que lo llevó a cabo? ¿Y dónde colocamos al probable clérigo/ consejero que habría ideado la iconografía más adecuada para la ornamentación? Nuestra conclusión es que sencillamente no se pueden separar estos factores porque la colaboración era imprescindible en el proceso artístico medieval.

\footnotetext{
$83+$ IN NOMINE DOMINI NOSTRI IHESU CHRISTI

OB ONORE SANCTI SALVATORIS

IELVIRA SANCES HOC FECIT

XEMENUS FECIT ET SCULPSIT ISTAM PORTICUM

ORATE PRO EO
}

Ver F. SimÓN Y NiETo, "El monasterio de San Salvador de Nogal. Estado actual, breve noticia de su historia, recientes descubrimiento epigráficos", Boletín de la Real Academia de la Historia 35 (1899), pp. 187210; J.L. SenRa Gabriel y Galán, "Nogal de las Huertas. Iglesia del monasterio de San Salvador», Enciclopedia del Románico en Castilla y León. Palencia, vol. II, (eds. M.Á. García GuíneA, J.M. Pérez González), Aguilar de Campoo, pp. 1099-1107. 